Linköping Studies in Science and Technology

Doctoral Thesis No. 1621

\title{
Multicomponent Alloying \\ for \\ Improved Hard Coatings
}

\author{
Rikard Forsén
}

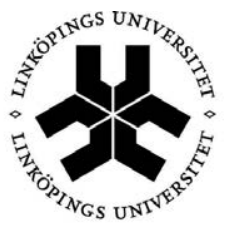

Linköping University

NANOSTRUCTURED MATERIALS

DEPARTMENT OF PHYSICS, CHEMISTRY AND BIOLOGY (IFM)

LINKÖPING UNIVERSITY, SE-58183 LINKÖPING

SWEDEN

LINKÖPING 2014 
The cover image shows an energy dispersive elemental map of a Ti-Cr-Al-N coating heated at $1100{ }^{\circ} \mathrm{C}$ for 2 hours, $\mathrm{Ti}$ (red), $\mathrm{Cr}$ (blue) and $\mathrm{Al}$ (green). The domain size is around 20 nanometers.

(C) Rikard Forsén, unless otherwise stated

ISBN: 978-91-7519-238-3

ISSN: 0345-7524

Printed by LiU-Tryck, Linköping, Sweden, 2014 


\section{Abstract}

Coatings are vital to protect and to increase the productivity of cutting tools in high speed and dry cutting applications. During the cutting operation the temperature may exceed $1000{ }^{\circ} \mathrm{C}$ it is therefore necessary that the coatings withstand high temperatures. A lot of development and research has been carried out during the last 30 years on finding new coating material systems providing enhanced properties such as adhesion, hardness and oxidation resistance at elevated temperatures. This thesis is based on multicomponent alloying of quaternary transition metal nitride hard coatings with a main focus on Ti-CrAl-N coatings. Many different coatings and compositions have been deposited using an industrial scale cathodic arc evaporation deposition system. All deposited coatings contain $\mathrm{Al}$ as this element is known to increase the hardness and the oxidation resistance of nitride coatings. The deterioration of the hardness in Al-containing nitride coatings is generally attributed to the transformation of cubic Al-N into hexagonal Al-N and the consequent domain coherency relaxation. This thesis investigates these phenomena on an atomic level providing a deeper understanding of and a way to engineer improved hard nitride coatings. The essence of this thesis is that by adding a third metal to a ternary nitride material system, for example one of the most frequently used Ti-Al-N, it is possible to tune and engineer the thermal stability of the cubic structure and the coherency strain which in turn affects the hardness and the oxidation resistance. The key point is that new intermediate phases in the decomposition process are generated so that the eventual detrimental phases are suppressed and delayed. More specifically, when $\mathrm{Cr}$ is added to the Ti-Al-N material system the coatings exhibit an age hardening process up to $1000^{\circ} \mathrm{C}$ caused by spinodal decomposition into coherent $\mathrm{TiCr}$ - and $\mathrm{AlCr}$-rich cubic Ti- 
Cr-Al-N domains. This means that the unstable cubic Ti-Cr-Al-N phase decomposes via yet another unstable cubic Cr-Al-N phase before the detrimental hexagonal transformation of Al-N takes place. The hardness is therefore retained up to a higher temperature compared to Ti-Al-N coatings.

By utilizing multicomponent alloying through addition of $\mathrm{Ti}$ to $\mathrm{Cr}-\mathrm{Al}-\mathrm{N}$ coatings the hardness is retained after annealing up to $1100{ }^{\circ} \mathrm{C}$. This is a dramatic improvement compared to Cr-Al-N coatings. Here the Ti addition promotes the competitive spinodal decomposition into $\mathrm{TiCr}$ - and Al-enriched domains suppressing the detrimental hexagonal Al-N formation.

To investigate the effect of multicomponent alloying for other material systems with different mixing free energies and atomic sizes, Zr-containing, Zr-Cr-Al-N and Zr-Ti-Al$\mathrm{N}$, quaternary nitride coatings have also been deposited. For high Al- and high Zrcontaining coatings the cubic solid solution structure is disrupted into a mix of nanocrystalline hexagonal and cubic phases with significantly lower hardness. The results show that the structure and hardness of these coatings are sensitive to the composition and in order to optimize the hardness and thermal stability the composition has to be finetuned.

Altogether it is shown that through multicomponent alloying and through the control of the coherency strain it is possible to enhance the hardness and the oxidation resistance compared to the ternary system which may lead to new improved functional hard coatings. 


\section{Populärvetenskaplig sammanfattning}

Hela det moderna samhället hänger starkt samman med användandet av nya avancerade produkter och tillverkningstekniker. Det kan vara fordon, elektroniska apparater, bostäder etc. Oavsett produkt är förbättringar nästan alltid baserade på att nya eller förbättrade material har upptäckts. Förbättrade material möjliggör exempelvis ett effektivare batteri, en reptålig skärm, en ny bensinsnålare motor, ett energieffektivare hus etc. En rådande omständighet är att många material idag designas och skapas på nanometernivå för att uppnå önskade förbättringar (1 nanometer motsvarar ungefär tjockleken av en tiotusendel av ett hårstrå). Ett typexempel på materialdesign på nanometernivå är transistorer som utgör grunden för all elektronisk utrustning. Transistorerna har hela tiden blivit mindre, snabbare och energieffektivare vilket har öppnat upp för nya användningsområden och produkter som sträcker sig över hela vardagslivet.

Ett annat område, som trots att det är en miljardindustri inte är lika känt för gemene man genom vardagliga produkter, är tillverknings- och bearbetningsindustrin av hårda material. Bearbetning av hårda material lägger grunden för exempelvis fordonstillverkning och gruvdrift. Här handlar det om att nya skär-, borr- och fräsverktyg möjliggör ett effektivare sätt att bearbeta materialen för att uppnå en ökad produktivitet. Det är just här som denna uppsats tar vid.

Skärverktygen är gjorda av hårda material som exempelvis volfram som bland annat används som värmdesköld till rymdfärjor så att de inte brinner upp i atmosfären vid landning. Trots att volfram erbjuder hög värmetålighet och hårdhet så är behoven av skyddande material för skärverktygen sedan långt tillbaka långt mer krävande. Temperaturen vid skäreggen kan uppgå till $1000{ }^{\circ} \mathrm{C}$ och för att förbättra egenskaperna 
hos skärverktyget beläggs detta med ett tunt keramiskt ytskikt (ungefär en tiondel av ett hårstrå). Dagens keramiska hårda ytbeläggningar kan öka produktiviteten (livslängden) hos verktygen upp till tio gånger. Inte nog med att det keramiska ytskiktet är hårt i sig, genom att designa materialen på nanometernivå kan ytskiktet fås att härda och bli ännu hårdare när det utsätts för höga temperaturer. I den här uppsatsen presenteras forskningsresultat som visar att genom att legera en kväve-baserad keramisk ytbeläggning bestående av flera metaller, såsom titan, krom och aluminium, kan materialets hårdhet öka och bevaras upp till $1100{ }^{\circ} \mathrm{C}$. Nyckeln till detta har visat sig vara att genom att blanda flera metaller så kan i vissa fall nya steg i den härdande processen uppstå som förstärker strukturen i materialet som genererar hårdhetsökningen. Genom dessa resultat kan man i framtiden erbjuda nya beläggningsskikt i industriell skala som förbättrar produktiveteten inom den skärande bearbetningen. 


\section{Preface}

This thesis is based on and an extension of my licentiate thesis Mechanical properties and thermal stability of reactive arc evaporated $\mathrm{Ti}-\mathrm{Cr}-\mathrm{Al}-\mathrm{N}$ coatings (Licentiate thesis No. 1546, 2012). It summarizes my work I have performed as a Ph.D. student in the Nanostructured Materials group at the Department of Physics, Chemistry and Biology (IFM) at Linköping University between January 2010 and August 2014.

Reactive arc evaporated multicomponent quaternary nitride hard coatings (Ti-Cr-Al-N, Zr-Cr-Al-N and Zr-Ti-Al-N) were deposited at Seco Tools AB in Fagersta using an industrial scale deposition system. The scientific output and the conclusions are primarily presented in the attached papers and the chapters build up a theoretical and experimental framework needed to comprehend the results.

The work has been supported by the Swedish Foundation for Strategic Research (SSF) through the project Designed Multicomponent Coatings, Multifilms. 



\section{Included Papers}

I Improving thermal stability of hard coating films via a concept of multicomponent alloying

H. Lind, R. Forsén, B. Alling, N. Ghafoor, F. Tasnádi, M. P. Johansson, I. A. Abrikosov, and M. Odén

Appl. Phys. Lett. 99, 091903 (2011)

II Decomposition and phase transformation in TiCrAlN thin coatings

R. Forsén, M. P. Johansson, M. Odén and N. Ghafoor

J. Vac. Sci. Technol. A 30, 061506 (2012)

III Nanostructuring and coherency strain in multicomponent hard coatings

R. Forsén, I.C. Schramm, P.O.Å. Persson, F. Mücklich, M. Odén and N. Ghafoor

Submitted for publication

IV Coherency strain engineered decomposition of unstable multilayer alloys for improved thermal stability

R. Forsén, N. Ghafoor and M. Odén

J. Appl. Phys. 114, $244303(2013)$

$\boldsymbol{V}$ Effects of Ti alloying of AlCrN coatings on thermal stability and oxidation resistance

R. Forsén, M. P. Johansson, M. Odén and N. Ghafoor

Thin Solid Films 534, 394 (2013)

VI High temperature phase decomposition in $T i_{x} Z r_{y} A l_{z} N$

H. Lind, R. Pilemalm, L. Rogström, F. Tasnadi, N. Ghafoor, R. Forsén, L. Johnson, M.P. Jöesaar, M. Odén and I.A. Abrikosov

Submitted for publication

VII Alloying as a tool for structure and thermal stability engineering of hard coatings R. Forsén, B. Syed, N. Ghafoor and M. Odén

$\underline{\text { In manuscript }}$ 


\section{Related but not included}

VIII Structure, deformation and fracture of arc evaporated $\mathrm{Zr}-\mathrm{Si}-\mathrm{N}$ hard films

K. Yalamanchili, R. Forsén, E. Jiménez-Piqué, M.P. Johansson Jöesaar, J.J. Roa, N. Ghafoor and M. Odén

In press, Surface and Coatings Technology

DOI: $10.1016 /$ j.surfcoat.2014.07.024 


\section{My contributions to the papers}

I I took part in the execution of the depositions, the experimental characterizations and in the planning and the compilation of the paper.

II I took part in the planning of the depositions, I carried out the depositions and the experimental characterizations and I wrote the paper.

III I planned the work and performed the depositions. I coordinated and took part in the experimental characterizations and I wrote the paper.

IV I planned the work, performed the depositions and the experimental characterization and I wrote the paper.

$\boldsymbol{V}$ I planned the work, performed the depositions and the experimental characterizations and I wrote the paper.

VI I took part in the execution of the depositions and the experimental characterization (TEM) and I took part in the planning of the project and the compilation of the paper.

VII I planned the work, performed the depositions and took part in the experimental characterizations and I wrote the paper.

VIII (not included) I took part in the execution of the depositions, the experimental characterizations and in the planning and the compilation of the paper. 



\section{Master's theses supervision}

Thermal Stability of cubic and nanocrystalline arc evaporated TiCrAlN coatings

H. Saleem

LITH-IFM-A-EX--12/2700-SE, 2014

I planned the project and performed the depositions and the annealing. I guided the student through the experimental characterizations and the thesis writing.

Thermal stability of arc evaporated $\mathrm{ZrCrAlN}$ coatings

B. Syed

LITH-IFM-A-EX--14/2854-SE, 2012

I planned the project and performed the depositions and the annealing. I guided the student through the experimental characterizations and the thesis writing. 



\section{Acknowledgements}

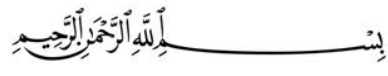

Magnus Odén, my supervisor

Naureen Ghafoor and Mats Johansson, my co-supervisors

Hans Lind, Ferenc Tasnádi, Björn Alling, Igor Abrikosov, Per Persson and Isabella Schramm for valuable contributions to my papers

Colleagues in the Nanostructured Materials, Thinfilm physics, Plasma and Coatings physics and Theoretical physics groups

Everyone who has helped me at Seco Tools in Fagersta

Family and friends 



\section{Table of content}

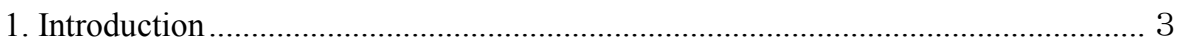

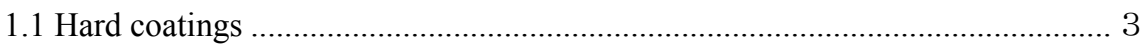

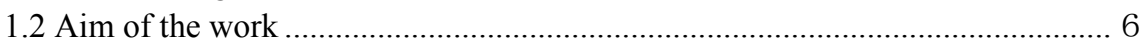

2. Phase instability and phase transformations ............................................................ 7

2.1 Mixing free energy and miscibility gaps........................................................ 10

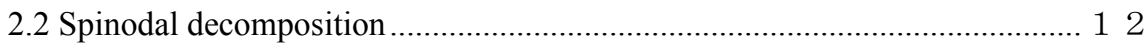

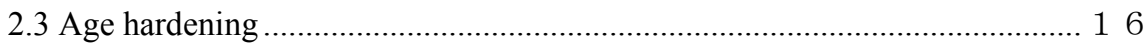

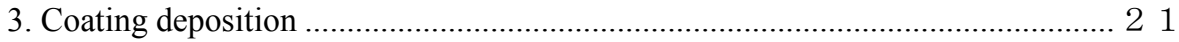

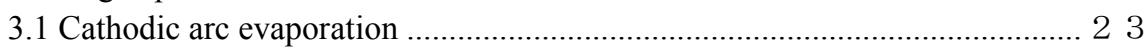

4. Coating characterization techniques .................................................................. 25

4.1 Transmission electron microscopy................................................................. 25

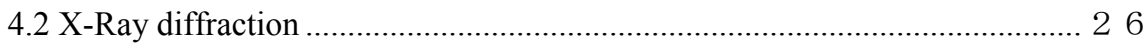

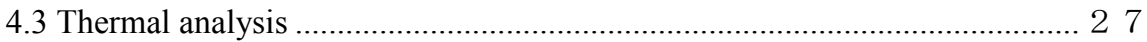

4.3.1 Differential scanning calorimetry …………………………………........ 28

4.3.2 Thermogravimetric analysis.................................................................. 30

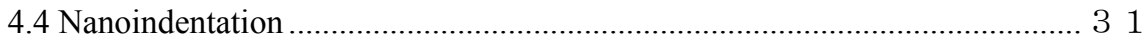

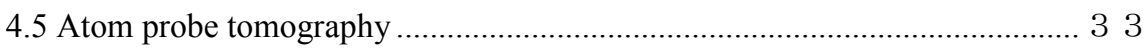

5. Materials for hard nitride coatings .................................................................... 35

5.1 Al-N based ternary coatings........................................................................... 36

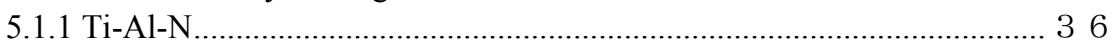

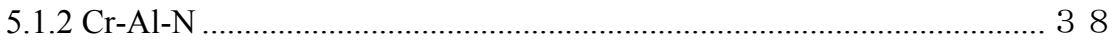

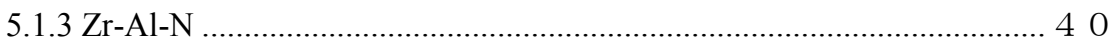

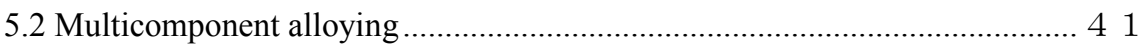

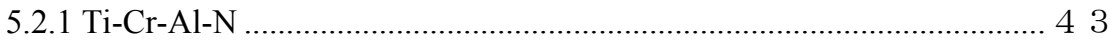

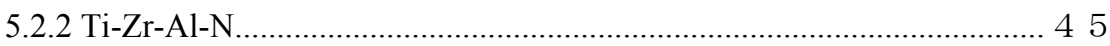

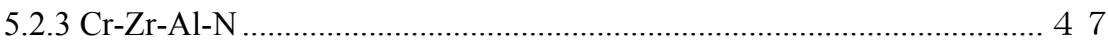

5.3 Multilayer multicomponent alloying................................................................ 49

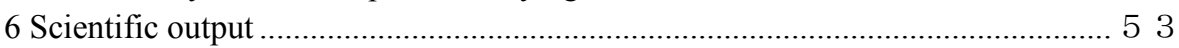

6.1 Summaries of the included papers …………………………………………. 53

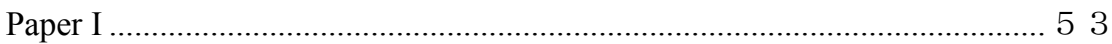

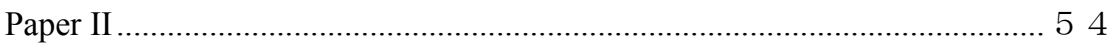

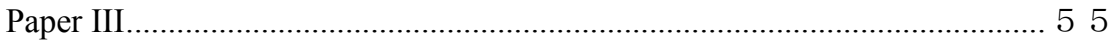

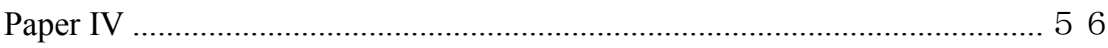

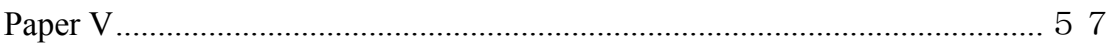

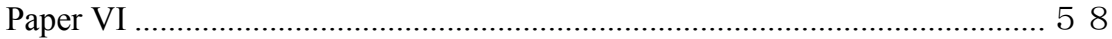

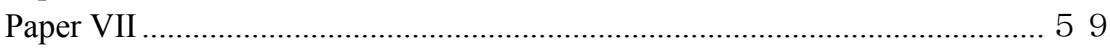

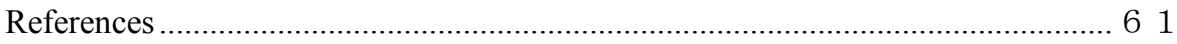




\section{Introduction}

\subsection{Hard coatings}

Applying a thin coating to a substrate makes it is possible to combine the properties of a bulk material with the properties of the coating material. Coatings may be found in a wide range of applications, for example electrical contacts, surface layers for corrosion resistance, enhancement of mechanical properties or for decorative purposes etc. ${ }^{1}$. More interestingly is that coating synthesis does not only allow for a combination of different properties of different materials, it also gives us the possibility of generating materials with new properties. Modern coating deposition techniques have the power to create coatings in thermodynamically unstable states. Such coatings may have considerably different properties compared to the thermodynamically stable elements and compounds naturally occurring in nature. This fact is utilized in hard coating industry to generate more favorable properties. The situation may be even more complex, the unstable state may not only give rise to new beneficial properties it may become even better when it decomposes via for example a phase transformation to more stable states. This phenomenon is also utilized for hard coatings where the hardness is not only very hard from the beginning it increases upon heat exposure during the cutting operation ${ }^{2}$. One important variable affecting the stability of the coating and the hardness increase is the temperature. Since the atoms have higher kinetic energy with increased temperature the atoms have a higher probability to diffuse and rearrange into more stable positions corresponding to a more stable state. 
The most stable state always prevails eventually, but the temperature controls the rate at which the decomposition takes place.

In the cutting tool industry protective coatings have been used since late $1960 \mathrm{~s}^{3,4}$. Around $90 \%$ of the cemented carbide cutting inserts used today are coated ${ }^{2}$. Coated cutting tools may have up to 10 times increased lifetime or productivity compared to uncoated tools. One of the early material systems used for protective coatings of cutting tools was Ti-N. The higher demands on cutting speed and feed rate, and to minimize the usage of cooling lubricants have to a large extent caused a replacement of Ti-N by Ti-Al-N which has been used in industry since the $1980 \mathrm{~s}^{5,6}$. Ti-Al-N is well described in the literature $7,8,9,10,11,12,13$ and it exhibits superior mechanical properties at elevated temperatures compared to $\mathrm{Ti}-\mathrm{N}^{5,}, 6,11,12$. The excellent mechanical properties arise thanks to a beneficial decomposition process of the unstable cubic Ti-Al-N material system occurring at temperatures around $800-900{ }^{\circ} \mathrm{C}$. The hardness of Ti-Al-N coatings increases upon high temperature exposure ${ }^{14,15}$. However, if the temperature is too high during cutting or the time duration of cutting is too long the Ti-Al-N coatings eventually undergo one unfavorable phase transformation forming hexagonally structured Al-N where the mechanical properties deteriorate. It is desirable to find a way to improve the thermal stability of the cubic structure and delay the hexagonal transformation in Ti-Al-N coatings to be able to improve the cutting performance further. There are many attempts and investigations aiming to increase the thermal stability of Ti-Al-N coatings ${ }^{11}, 12,13,16,17,18,19,20$. In some studies the effects of adding a third metal, for example $\mathrm{Y}, \mathrm{Nb}$, Hf or $\mathrm{B}$, to the Ti- 
Al-N material system have been investigated ${ }^{21,22}$. Other approaches involve concepts of multilayer growth ${ }^{8,23}$, where the coating architecture affects the decomposition process. It has been shown that by adding Cr, forming Ti-Cr-Al-N coatings, the hardness is increased and the wear rates may be lowered ${ }^{24,25,26,27}$. This thesis investigates deeper into Ti-Cr-Al-N coatings and explains the fundamental mechanisms behind the improved thermal stability and the improved hardness exhibited for these coatings compared to Ti-Al-N.

Oxidation is also a potential problem which may lead to deceased cutting performance and insufficient substrate protection. Oxidation is promoted when the coating is exposed to elevated temperatures. $\mathrm{Cr}-\mathrm{Al}-\mathrm{N}$ is a material system that shows superior oxidation resistance compared to Ti-Al- $\mathrm{N}^{28}$. However $\mathrm{Cr}-\mathrm{Al}-\mathrm{N}$ coatings do not demonstrate the aforementioned age hardening to the same extent as in Ti-Al-N ${ }^{29}$. This means that Cr-Al-N coatings have a lower hardness at working temperatures during metal cutting and are therefore not suited for high abrasive applications. This thesis demonstrates that there is a tradeoff between good oxidation resistance and high hardness when alloying Cr-Al-N with Ti coatings.

To generate a more general understanding of how multicomponent alloying may be used to generate improved hard coatings, two additional material systems, Zr-Ti-Al-N and $\mathrm{Zr}-\mathrm{Cr}-\mathrm{Al}-\mathrm{N}$, have also been studied. By alloying Al-N with combinations of $\mathrm{Cr}-\mathrm{N}$, $\mathrm{Zr}-\mathrm{N}$ and Ti-N it is possible to synthesize unstable coatings with different mixing free energies. If the driving force for decomposition becomes too large the structure becomes nano-crystalline with a significantly lower hardness. 
Experimental investigations have been conducted in parallel with theoretical work yielding an understanding of how the driving force for (spinodal) decomposition and the lattice parameter mismatches between the alloying elements depend on the metallic concentrations and affect properties such as hardness, oxidation resistance and thermal stability. The experimental techniques include aberration corrected and uncorrected scanning transmission electron microscopy ((S)TEM), x-ray diffraction $(X R D)$, differential scanning calorimetry $(D S C)$, thermogravimetric analysis $(T G A)$, atom probe tomography $(A P T)$ and nanoindentation. The combination of these characterization tools has allowed for detailed studies on an atomic scale of the decomposition processes responsible for age hardening.

\subsection{Aim of the work}

The main focus is to explore the decomposition process of Ti-Cr-Al-N coatings and thereby explore how multicomponent alloying may be utilized to generate improved hard coatings. 


\section{Phase instability and phase transformations}

Throughout this thesis the word domain is frequently used, and it means a nanometersized phase with either cubic or hexagonal crystallographic structure with variation in chemical composition.

The phase stability of a coating material is an essential property when it comes to the performance of the coating. Different phases may have significantly different properties such as adhesion, hardness or oxidation resistance. However, the existing phases within the coating are not the only important factor. There may also be beneficial phase transformations occurring in the coating. The driving forces for the transformations are related to the relative stability between the phases. The temperature provides the kinetic energy for the atoms to rearrange and the temperature is therefore controlling the rate. It should be pointed out that the driving force itself depends on the temperature where a certain phase may be unstable at room temperature but stable at $1000{ }^{\circ} \mathrm{C}$. This means that even though the atoms have a higher kinetic energy at $1000{ }^{\circ} \mathrm{C}$ compared to room temperature no transformation would occur without any driving force. All systems are continuously striving for minimization of their energy. The measured temperature is an averaged quantity of the kinetic energy where some atoms have less and some have higher energies than average. Therefore, if long enough time is given to any system in a given environment it will eventually transform into its most stable form. Inorganic materials found in nature are therefore normally stable since the material has had long time to minimize 
its energy after millions of years in the ground. However, normally it is not possible to assume that a material is in its stable form. Because many materials might have been formed under extreme conditions such as high temperatures or high pressures, for example solid crystalline rocks found inside mountains or oil deep down in the ground. When the oil is pumped up and exposed to a lower atmospheric pressure and lower temperatures or the crystalline rock is refined and separated the materials may no longer be in equilibrium with the environment. The material may still remain in its state for an extremely long time and it is the energy differences between the present phase and the stable phase that determine the magnitude of the force driving the transformation. Since some transformations apparently do not occur spontaneously there must be some mechanism preventing the system from transforming into its stable phase with a lower energy. Mathematically, this may generally be described by a local minimum in the energy.

In reality there may exist several different local minima corresponding to different phases for a certain material in different environments. The difference in energy for the local minima and the energy of the stable state in a certain environment is usually referred to as free energy or Gibbs free energy. In figure 1 the free energy of a system is depicted. The system has a local minimum in point E surrounded by energy barriers which the system has to overcome before the system can transform into state D with lower energy. The barriers may for example arise due to the spatial rearrangement of the atoms necessary to transform into state D or due to the energy cost of creating compositional gradients. 


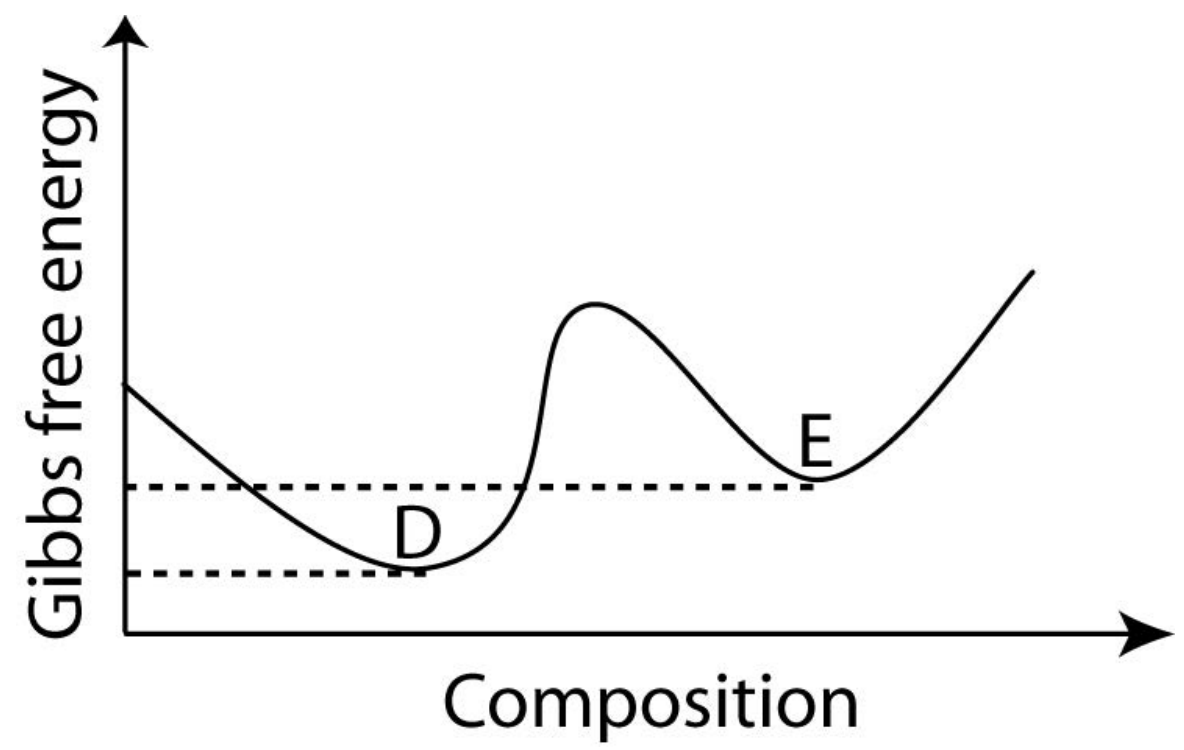

Figure 1 shows the Gibbs free energy of an arbitrary system with two local minima $D$ and $E$.

In this work different quaternary material systems with many different compositions have been studied. Almost all coatings are more or less unstable but remain in their unstable states for a very long time unless the temperature is increased several hundred degrees. Because of the very high temperatures required to drive the transformations within reasonable timeframes these coatings are sometimes said to be in meta-stable states. A clue for these meta-stable states can be found by studying the free energy for a certain structure. For compositions where the mixing free energy is higher compared to the energy of the separated phases, it is said that there is a miscibility gap between the alloyed components and it means that the solid solution is unstable. 


\subsection{Mixing free energy and miscibility gaps}

When two or more components are immiscible it requires energy to mix them. But since the coating synthesis is carried out at a relatively low temperature of $300-400{ }^{\circ} \mathrm{C}$ the atoms are cooled rapidly at the substrate. The limited kinetic energy of the atoms prevents diffusion and transformations into equilibrium states. In other words, it is possible to synthesis materials in unstable states where immiscible components are randomly mixed. In figure 2 the mixing free energy of cubic (c)-Ti-Cr-Al-N $\mathrm{N}^{9,30}$ at zero Kelvin and at $1000{ }^{\circ} \mathrm{C}$ are shown. The mixing free energy at zero Kelvin is positive almost all over the ternary plane except for compositions along the $c$ - Ti-Cr-N ternary. This means that almost all solid solutions of $c$-Ti-Cr-Al-N are unstable. The most immiscible component is $c$-Al-N and it has the highest energy gap versus $c-\mathrm{Ti}-\mathrm{N}$. By increasing the Cr-content the system becomes less unstable. When the temperature is increased the atoms have higher kinetic energy and the coating would decompose at a high rate into its stable state, which in this case are the $c-\mathrm{Ti}-\mathrm{N}, c-\mathrm{Cr}-\mathrm{N}$ and $c-\mathrm{Al}-\mathrm{N}$ binaries. But as seen in Figure 2 (b) the theoretical predictions suggest that mixing free energy at a temperature of $1000{ }^{\circ} \mathrm{C}$ is overall reduced and is negative for some compositions. This means that there is no driving force for decomposition at higher temperatures for some of compositions, in particular close to the Ti-Cr-N ternary. 


\section{Mixing free energy:}

$$
\Delta G=G\left(\operatorname{Ti}_{x} C r_{y} A l_{z} N\right)-x G(T i N)-y G(C r N)-z G(A l N)
$$
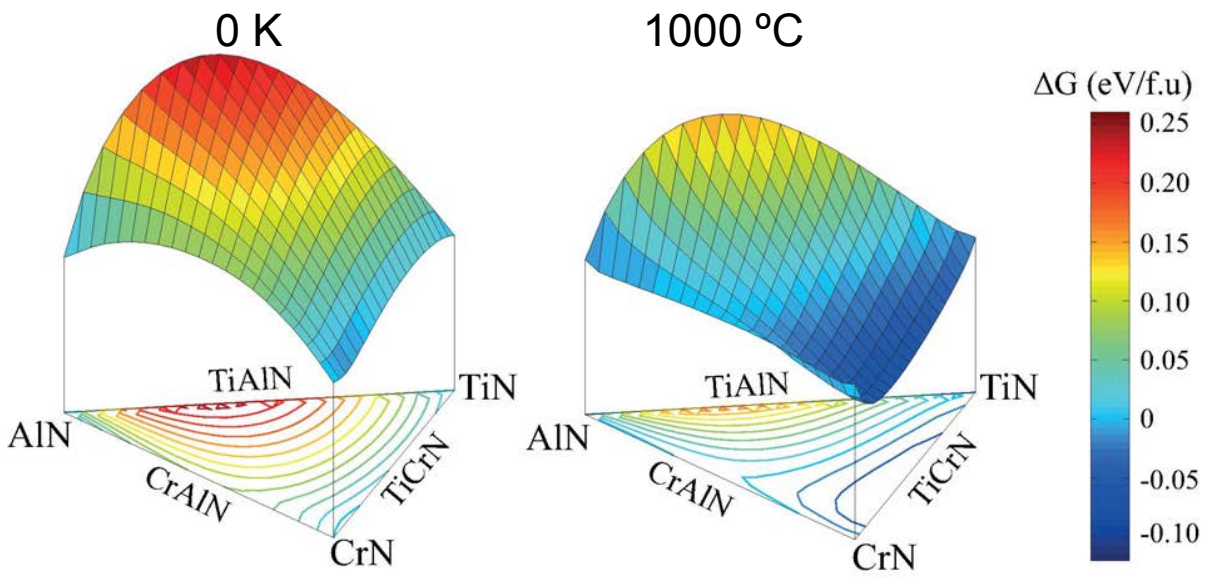

Figure 2 shows the mixing free energy of $c$-Ti-Cr-Al-N at zero Kelvin and $1000{ }^{\circ} \mathrm{C}$.

However, these calculations are only valid for the cubic crystal structure $(f c c)$ but since $c-\mathrm{Al}-\mathrm{N}$ is not stable there is a driving force for the transformation of $c-\mathrm{Al}-\mathrm{N}$ into hexagonal (h)-Al-N. Compared to $c-\mathrm{Cr}-\mathrm{N}$ there are also more stable phases like hexagonal $\beta-\mathrm{Cr}_{2}-\mathrm{N}$ and metallic $b c c-\mathrm{Cr}$. However, as shown in paper II, these transformations are less important from an application point of view since they are formed at higher temperatures between 1300 and $1400{ }^{\circ} \mathrm{C}$ where the hardness of the coating has already deteriorated because of the transformation to $h-\mathrm{Al}-\mathrm{N}$.

The decomposition of any unstable alloy with a composition within the miscibility gap occurs with one important condition. The initial overall composition remains constant since no new elements are created nor destroyed. This means that if for 
example the $\mathrm{Al}$ content decreases somewhere due to segregation in the coating it has to increase somewhere else. If this should occur and dominate the microstructure the net result of such segregation must be an overall energy decrease. If the second derivative of the free energy is negative any elemental segregation or fluctuation will always result in an overall energy decrease. Within a compositional range where this condition is fulfilled is called the spinodal and the segregation process of the immiscible components inside a material within this region is called spinodal decomposition.

\subsection{Spinodal decomposition}

At points $\mathrm{B}$ and $\mathrm{C}$ in figure 3 the second derivative of the Gibbs free energy is zero (where the slope is at maximum). In-between points $\mathrm{B}$ and $\mathrm{C}$ the net result for any compositional fluctuation will always be an overall energy decrease. This range is called the spinodal and is defined as $\frac{\partial^{2} G}{\partial^{2} c}<0$. In multicomponent alloys the spinodal may define a two dimensional landscape of compositions fulfilling this condition. 


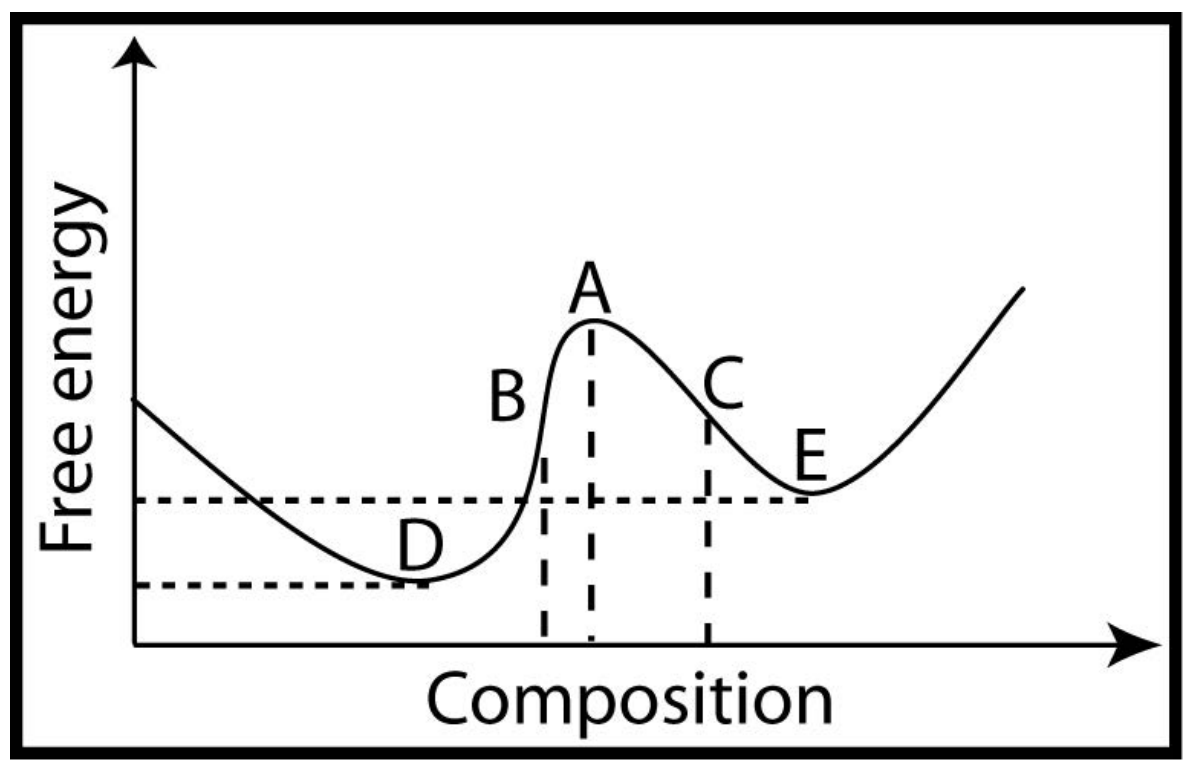

Figure 3 shows the free energy versus composition of an arbitrary system with a local maximum in point $A$, a spinodal region between points $B$ and $C$ and a binodal region between points $D$ and $E$.

If the composition of an alloy system is at point A in figure 3, its energy is a local maximum and lies within the spinodal region. Here the system is unstable without any barriers for transformation. Since any compositional change will lower the energy no nuclei (defects, grain boundaries etc.) are needed to initiate the segregation of the elements. This is in contrast to the case when the composition lies outside the spinodal where there is a critical domain size above which growth is energetically favorable. An elemental segregation taking place within the spinodal region is called spinodal decomposition and leads to a microstructure with some typical characteristics. Since no nuclei are required, the segregation occurs uniformly in the material. Because no nuclei need to form the segregation may also take place iso-structurally. This is the 
case for both Ti-Al-N and Ti-Cr-Al-N coatings where coherent cubic Ti- and Al-rich domains are created. The iso-structural decomposition and the consequent coherency strain is the key behind the hardness increase of the coatings at elevated temperatures and will be discussed more in upcoming chapters. During the decomposition of the coating the energy is decreased but the decrease in mixing free energy as the elements segregate is counteracted by the energetic cost of creating compositional gradients (surface tension). It turns out that a domain size satisfying equation $1^{31,32}$ will grow faster than all other sizes and this size will therefore dominate the microstructure. Given that the segregation occurs homogenously throughout the material and that the domain size distribution is relatively uniform, the domain size and the chemical composition are sometimes referred to as wavelength and amplitude because of the similar description of a harmonic linear oscillator. The compositional amplitude increases during the spinodal decomposition but the wavelength remains constant. Eventually a coarsening process begins which decreases the energy further. Figure 4 depicts how the compositional fluctuations evolve with time during the spinodal decomposition and the subsequent coarsening starting from a homogenous solid solution.

$$
\lambda=\sqrt{2} \sqrt{\frac{8 \pi^{2} \kappa}{\frac{\partial^{2} G}{\partial^{2} c}}} \quad \kappa=\text { surface energy }
$$

\section{Eq. 1}




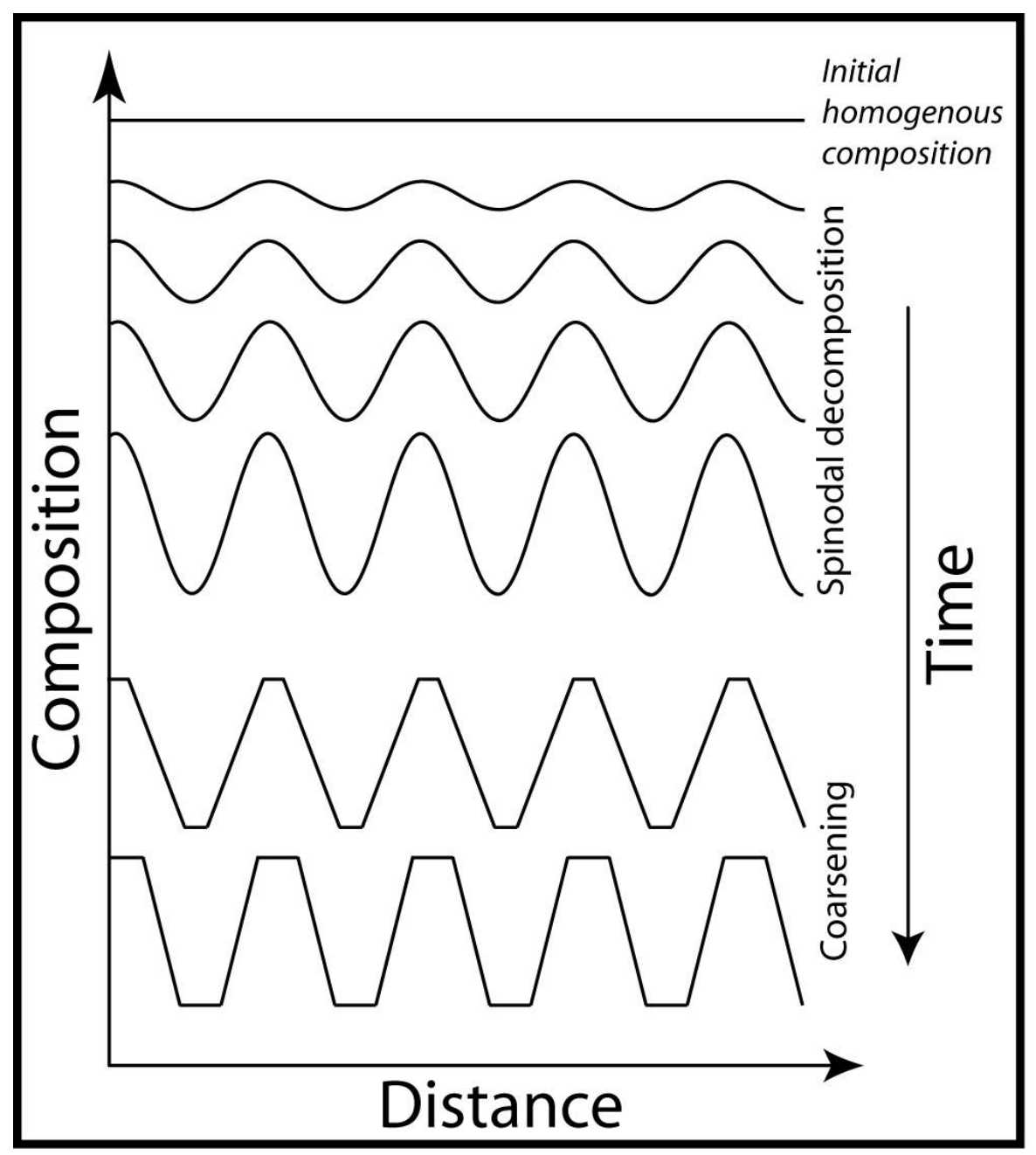

Figure 4 shows the compositional modulation versus distance at different times during spinodal decomposition and the subsequent coarsening.

Most of the results in this thesis are based on studies of post-deposition annealed coatings. The microstructure of these coatings is many times a result of the coarsening process rather than an observation of the preceding spinodal decomposition. This is 
because the critical wavelength is usually small (a few nanometers) during the spinodal decomposition making it difficult to observe with the analytical instruments that have been used. The spinodal decomposition also seem to occur fast and the onset of the coarsening process begins instantaneously at high temperatures around 1000$1100{ }^{\circ} \mathrm{C}$. The main reason for giving so much attention the spinodal decomposition is that it this is the mechanism behind the age hardening (hardness increase) and the successful utilization of these hard protective coatings.

\subsection{Age hardening}

When coatings are deposited using reactive cathodic arc evaporation there is a high concentration of interstitials, vacancies and dislocations as seen in the diffraction contrast micrograph in Figure 5. This yields high stresses and a high hardness of the coatings in their as deposited states ${ }^{33,34}$. The high concentration of lattice defects means that the coatings are not in equilibrium and when the temperature is increased the coatings recover and the number of defects is decreased and the stress and the hardness decreases ${ }^{35,36}$. The recovery process is an irreversible process and is typically observed as a hardness decrease after post-deposition annealing. 


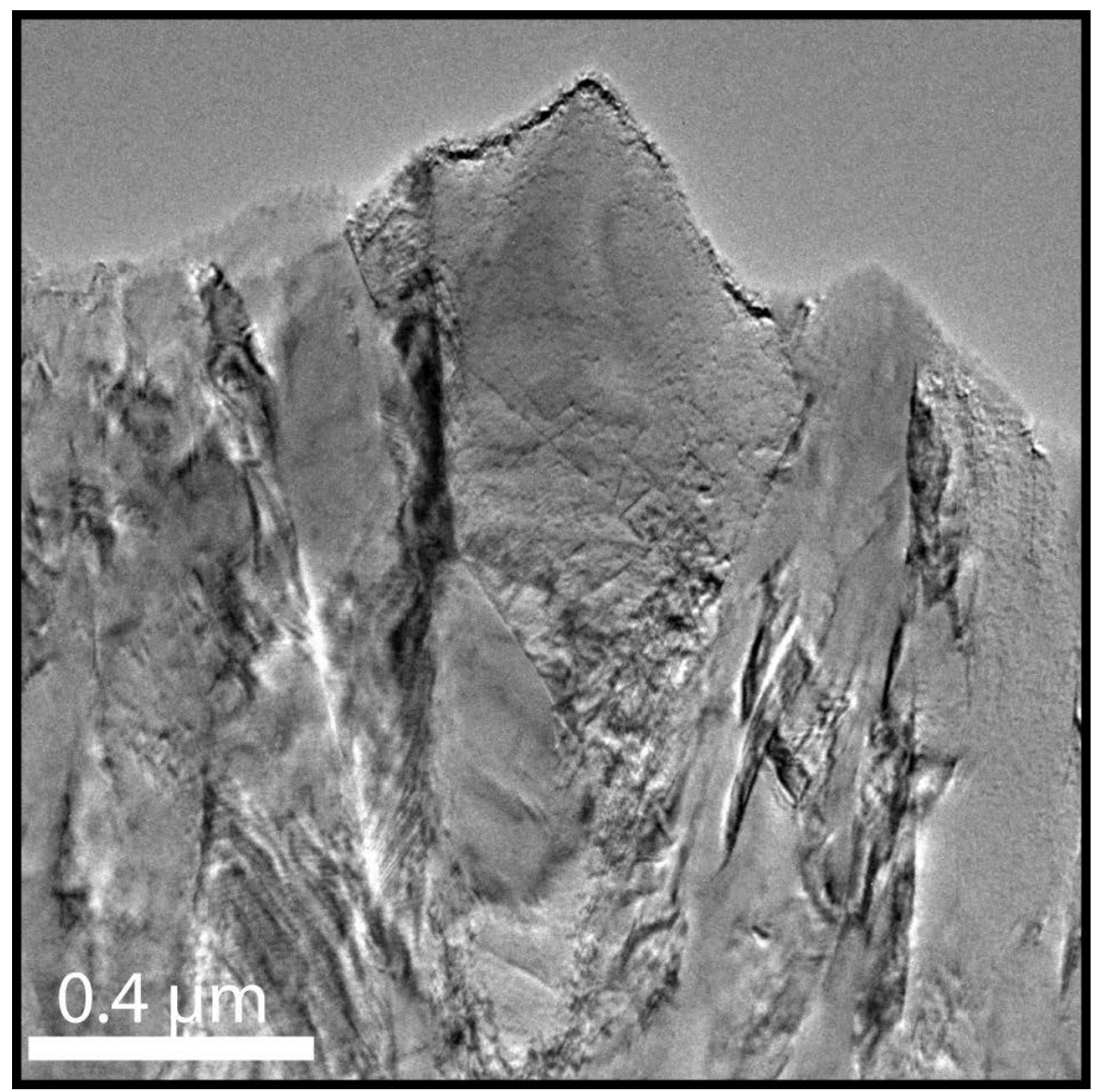

Figure 5 shows an overview TEM micrograph of a cathodic arc evaporated Ti-Cr-Al-N coating in its as deposited state. The coating has a high density of defects.

The hardness of the coating is a crucial factor influencing the cutting performance during metal machining. The high temperature hardness is of particular interest since the metal machining operation generates very high temperatures. Given the difficulty of measuring the hardness at elevated temperatures, the coatings in this work have been annealed at different temperatures and the hardness has thereafter been measured 
at room temperature. The hardness is strongly related to the dislocation movement in the coating causing plastic deformation. The hardness can be improved by introducing different means to obstruct the movement of the dislocations. For example, the dislocation movements may be altered if nanometer-sized coherent regions with different composition and elastic constants are formed in the material. As described earlier spinodal decomposition is a process forming such regions.

Because of the different lattice parameters of the binary phases in Ti-Cr-Al-N there is an increasing strain energy associated with the coherent segregation of the elements during the spinodal decomposition. The strain increases the force required for a dislocation to move across domains with different compositions. Thus, the movement of the dislocations is obstructed and the material becomes harder. The requirement for this mechanism is that the domains remain coherent otherwise the strain is relaxed and the hardening effect is $\operatorname{lost}^{11,13,19,37}$. When the domain size increases during the coarsening process the coherent cubic Al-enriched domains become more and more energetically unfavorable. Eventually the cubic structure transforms into $h$-Al-N and the strain relaxes. The material is then over-aged resulting in a lower hardness ${ }^{11,13}$. Figure 6 shows the hardness versus annealing temperature of different Ti-Cr-Al-N alloys. Cr-Al- $\mathrm{N}^{29}$ exhibits only the recovery process where the hardness decreases while Ti-Al- $\mathrm{N}^{8}$ and Ti-Cr-Al-N show different degrees of age hardening and overageing. 


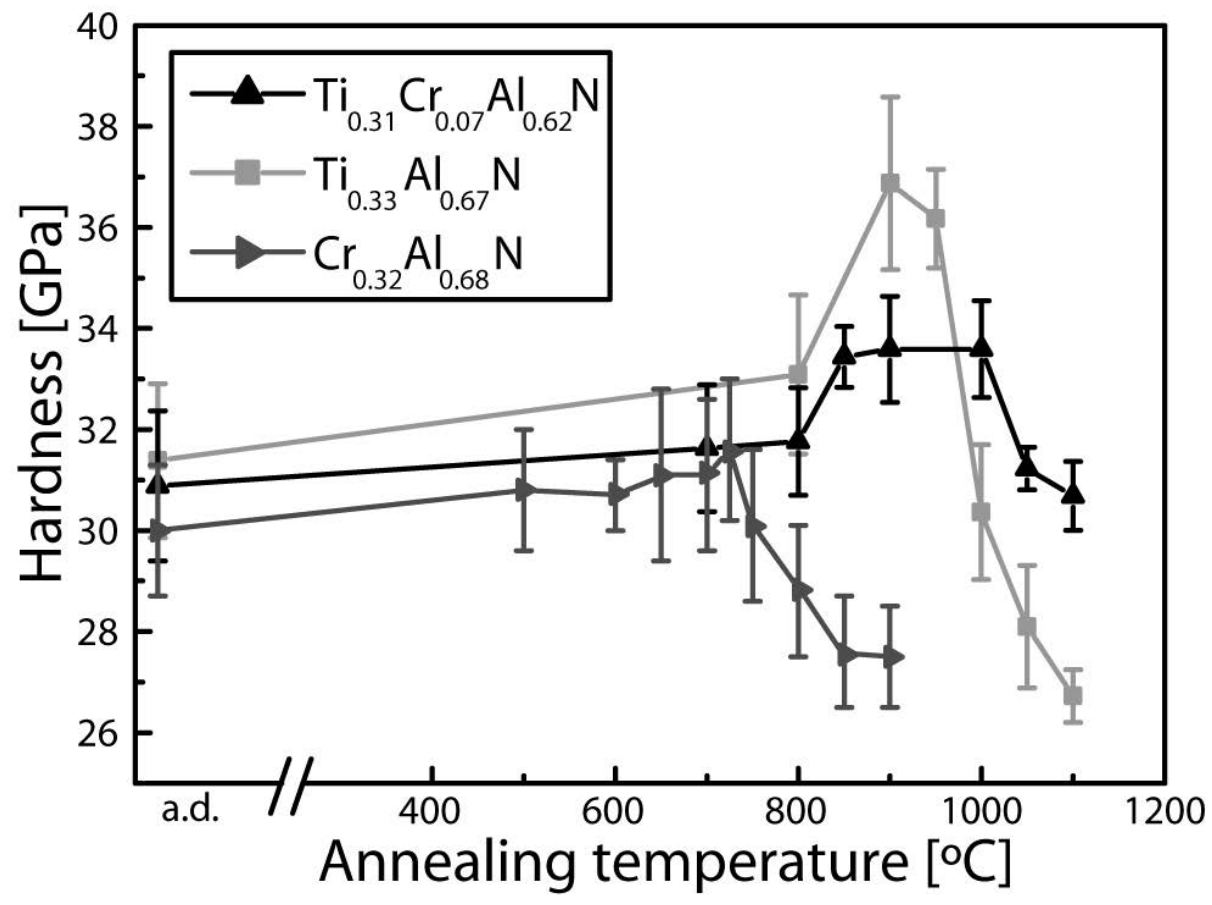

Figure 6 shows the hardness versus annealing temperature of $\mathrm{Cr}-\mathrm{Al}-\mathrm{N}^{29}$, Ti-Al- $\mathbf{N}^{8}$ and $\mathrm{Ti}-\mathrm{Cr}-\mathrm{Al}-\mathrm{N}$. Cr-Al-N exhibits only a recovery process whereas Ti-Al-N and Ti-Cr-Al-N exhibit different degrees of age hardening and over-ageing. 


\section{Coating deposition}

There are many different methods to deposit coatings. Some are better suited for certain applications compared to others. Usually it is the application and the desired properties of the coating that will decide which technique is best suited. The properties may include demands on the coating thickness, adhesion, shape and dimensions of the substrate, electrical conductivity, substrate material, level of impurities incorporated in the coating etc. Generally speaking, the same material deposited with different techniques may exhibit different properties. The other way around usually also holds true, the properties of the coating deposited with the same method will differ depending on the deposited materials, substrate material, impurities, temperature, substrate bias voltage etc. The deposition process may be very sensitive and unstable meaning that by changing one parameter, for example the substrate bias, many other parameters such as the plasma density, temperature, composition in the film, stress levels etc. may also be affected. These changes may have dramatic consequences for the properties and performance of the coating. One way to describe the general relationships between deposition, structure and the properties is presented in equation 2. This equation is often referred to as the material science paradigm. 
From equation 2 it can be seen that if certain properties are wished for, the structure and the composition of the coating have to be in accordance and meet those requirements. In order to get the structure and the composition right the deposition process has to be conducted accordingly. It is worth considering that the equivalence applies on all sides of the equation. For example, to achieve a particular structure requires the correct deposition process which will also determine the properties of film. Cathodic arc evaporation belongs to a category of physical vapor deposition $(P V D)$ techniques $^{38}$. It is desirable to have a high level of ionization to be able to control the impact kinetic energy and thus the surface mobility of the impinging atoms through the substrate bias $^{39}$. The depositions are usually carried at relative low temperatures between $300-500{ }^{\circ} \mathrm{C}$. These low temperatures make it easy to deposit coatings in unstable state as the atoms are not provided high enough energy to diffuse and rearrange to their equilibrium positions during the deposition. Using cathodic arc evaporation the degree of ionization is very high, close to $100 \%{ }^{40}$. For other PVD techniques like sputtering the ionized fraction of the deposited material is very low, however the technique can be improved by sputtering in a so called high power impulse mode (HIPIMS) ${ }^{41}$ but the cost is usually a lower deposition rate ${ }^{42}$. All the coatings deposited in this work have been performed using an industrial scale cathodic arc evaporation system. 


\subsection{Cathodic arc evaporation}

The desired material for the coating is fabricated into a solid piece called cathode and it may consist of either one element or a compound of different elements. In order to evaporate and transport the atoms from the cathode to the substrate while avoiding impurities from the air in the coating, the deposition takes place in a vacuum chamber. The coatings in this work are ceramic nitrides but the cathodes are metallic, therefore the ejected atoms from the cathode need a way to react with nitrogen. This is achieved by introducing nitrogen gas with a low pressure of a few $\mathrm{Pa}$ in the chamber during the deposition. This is called reactive cathodic arc evaporation. To initiate the evaporation process a very high current is fed through the cathode surface using a trigger rod. The high current density results in a local arc sport causing a small part to melt and evaporate ${ }^{43}$. In order to have a constant flow of ejected species the location of the arc is continuously shifted over the cathode surface using magnetism. While the arc spot is rotating and oscillating over the surface ejecting material from different parts of the cathode including anything from single atoms to larger micrometer sized chunks of material may be deposited on the substrate. The larger pieces of material are referred to as macroparticles. These macroparticles will affect the properties of the coating by for example shadowing the deposition flux generating detrimental voids, introducing stress in the vicinity of the particles or by increasing the surface roughness of the coating. The macroparticles are positively charged and the amount in the coating can be decreased by utilizing magnetic filter setups between the cathode and the substrate.

This will usually come at a high cost of lowering the deposition rate ${ }^{44}$. The high 
current density in the arc sport provides high enough energy to ionize the ejected species from the cathode. The result is a mix of freely moving charged ions, defined as plasma ${ }^{45}$, with a directed flux from the cathode towards the substrate. The successfulness of the process is also dependent on the material that is evaporated. Pure Al cathodes are for example very difficult to use for cathodic arc evaporation because of the low melting temperature and the low conductivity of $\mathrm{AlN}^{46}$. Therefore no coatings with higher Al-content than $\sim 70 \%$ have been deposited in this work. 


\section{Coating characterization techniques}

There are many different characterization techniques especially developed for hard coatings or thin films. There are plentiful of literature describing each technique and several books covering each of them can easily be found. Here follows short summaries of the essence in each technique that has been used in the research of this thesis.

\subsection{Transmission electron microscopy}

It is known from the Rayleigh criterion that the minimum resolvable distance is proportional to the wavelength of the radiation. Therefore the resolution of light optical microscopes is limited by the wavelength of visible light, $\sim 10^{-7} \mathrm{~m}$. When electrons are accelerated to $200 \mathrm{kV}$ the wavelength of the electron radiation is around $10^{-12} \mathrm{~m}$. This is a theoretical improvement of five orders of magnitude compared to a light optical microscope. The true resolution in practice is however limited by lens imperfections of the microscope. The development of new microscopes and correction techniques is continuously ongoing and with the most advanced transmission electron microscopes today, Angstrom resolution ( $\sim$ radius of an atom, $10^{-10} \mathrm{~m}$ ) can be achieved.

Since the mean free path of electrons in solid materials is very short, $\sim 10^{-9} \mathrm{~m}$, the sample has to be very thin. Sample preparation is not just tedious routine work, good sample preparation is essential to benefit from the high resolution that the microscope may have. If features with a size of a few nanometers are about to be studied the sample thickness should be on the same scale. If the sample is too thick the projected 
image generated by the electrons transmitted through the material will contain information from overlapping features. Once a thin sample has been prepared it is possible to observe and measure for example compositional fluctuations down to an atomic scale, lattice parameters and obtain diffraction patterns from nanometer-sized areas. Using an electron microscope with correctors to compensate for spherical aberration (the focus point is different depending on the distance from the optical axis the light enters) was essential to achieve the high resolution results presented in paper III.

\subsection{X-Ray diffraction}

In contrast to the time consuming sample preparation required before using transmission electron microscopy, $\mathrm{x}$-ray diffraction measurements require almost no preparation. Using photon radiation instead of electrons the measurement does not have to be carried out in vacuum. By shining light in the x-ray wavelength region of $\sim 10^{-10} \mathrm{~m}$ onto the sample the incidence radiation will be backscattered spherically in all directions by the atoms in the sample. If there is some kind of periodicity among the atoms in the sample the scattered radiation will interfere constructively in specific directions. The constructive interference can be measured by collecting the scattered light on an x-ray detector. Constructive interference will occur when the path length difference between scattered light from different interatomic planes correspond to a multiple of the wavelength of the x-ray source. When applying this technique the 
lattice parameter or the interatomic distances in the sample can be extracted through equation 3 (Bragg's law) since the wavelength and the geometry are known variables. By measuring the distance, $\mathrm{d}$, between the atoms in a sample the crystal structure and the phases present in the sample can be determined.

$n \lambda=2 d \sin \theta$

eq. 3

( $\mathrm{n}$ integer, $\lambda$ wavelength, $\mathrm{d}$ distance between two adjacent planes, $\theta$ scatter angle)

\subsection{Thermal analysis}

By thermal analysis it is meant that any transformation or microstructural change in the sample is monitored in-situ as the sample is somehow heat treated. Most of the coatings in this work are deposited in more or less unstable states. The mechanical properties and the oxidation resistance of the coatings are directly coupled to their microstructure. Monitoring the microstructure evolution of hard coatings upon heat exposure is therefore of high interest. As the unstable coatings are exposed to high temperatures, the higher kinetic energies allow the atoms to diffuse and rearrange into positions corresponding to a more thermodynamically stable state. This may be in terms of a phase transformation where the crystal structure is changed, stress relaxation or crystallization of amorphous regions. The high temperature exposure may also lead to spinodal decomposition as discussed in chapter 2.2. The net energy change during of a phase transformation or any other change in the coating is that heat gives rise to heat either being released, called an exothermic reaction, or absorbed, called an 
endothermic reaction. In this work these two reaction types have been measured in-situ with a technique called differential scanning calorimetry (DSC).

\subsubsection{Differential scanning calorimetry}

When there is an exothermic or an endothermic reaction occurring in the sample the energy required to raise the temperature of the sample is either lower or higher compared to a reference sample with a known thermal response. The output signal from the instrument is the difference in energy required to raise the temperature between the sample and the reference sample. In this work the reference material is simply an empty inert sapphire sample holder that remains stable without any reactions up to the studied temperatures of $1400{ }^{\circ} \mathrm{C}$. The samples were heated with a predefined heating rate $\left(20^{\circ} \mathrm{C} / \mathrm{min}\right.$ in this work $)$. With a higher heating rate the signal peaks are shifted to lower temperatures meaning that the heating rate has to be the same in order to make a direct comparison with other data.

During the heating it may be assumed that all transformations in the coating are irreversible and that after one heating cycle the coating is in a more stable state, or possibly its equilibrium state, and no more reactions would occur if the sample is heated a second cycle. A second heating cycle is usually performed which is used for background subtraction to clearly distinguish between the energy release or absorption due to phase transformation in the coating from the energy required to heat the inert sample holders or instrument errors. The main problem using DSC for coatings is that the coatings are very thin in comparison to the substrates. If both the substrate and the 
coating would be measured together the signal from the substrate would completely dominate the signal. Somehow the substrate has to be removed in order to measure the thermal response from the coating. This is a very tedious work. In fact, the work required to prepare one DSC sample normally exceeds the work required for preparing a sample for transmission electron microscopy (a process which normally is considered as tedious). The preparation begins by depositing the coating onto special substrates (Fe foils) with a preferably large coating thickness of around $\sim 10 \mu \mathrm{m}$. This means that whether DSC should be used to characterize the coatings or not, has to be planned already at the deposition stage since many Fe foils have to be mounted in the deposition chamber and the deposition time has to be set to obtain the desired thickness. The Fe foils are electrically conductive and this is a requirement in order to apply and maintain a constant bias potential to the substrate. The Fe foils are also mechanically strong enough to withstand the mechanical stress induced during the deposition. The coated Fe foils are thereafter mechanically grinded and dissolved in hydrochloric acid. A schematic of the sample preparation is presented in figure 7 . The compositions of the studied coatings in this work were unchanged by the hydrochloric acid (confirmed with EDX) but it might not be the case for other materials. The end result of the sample preparation is a powder sample ready for thermal analysis (the powder is also excellent to use for x-ray diffraction since the substrate peaks are completely avoided which was utilized in paper V). 


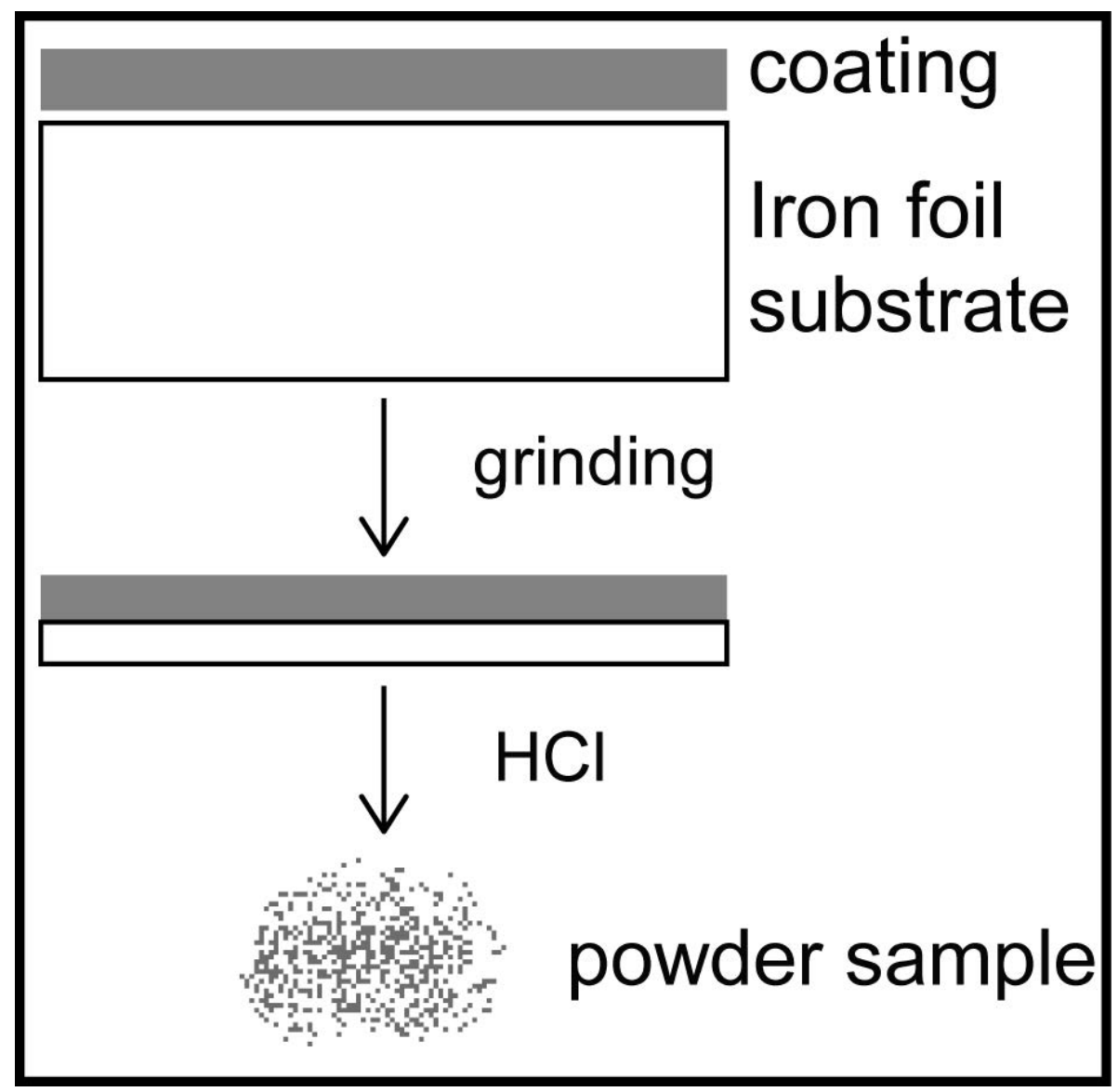

Figure 7 shows the DSC sample preparation. A coated Fe-foil. Middle, Fe-foil partially removed through mechanical grinding. Fe-foil completely removed through chemical etching and the process ends with a powder sample.

\subsubsection{Thermogravimetric analysis}

In some cases the interesting phase transformations alter the mass of the sample. This

is the case when there are species evaporating from the sample like the nitrogen atoms 
in all of the studied Cr-containing coatings. Another example of a process where the mass change plays an essential role is in the analysis of the sample oxidation resistance. As the nitrogen atoms are replaced by the heavier oxygen atoms the overall mass of the sample increases. The oxidation may also result in an alteration of the stoichiometry for example the oxidation of $\mathrm{Ti}-\mathrm{N}$ into $\mathrm{TiO}_{2}$ resulting in an even more pronounced mass increase. By monitoring the mass change in-situ while increasing the temperature it is possible to study and quantify the oxidation on-set temperature and the oxidation rate. This experimental technique is called thermogravimetric analysis (TGA) and is possible to perform with the same equipment used for DSC allowing for a simultaneous measurement of the thermal response and the mass change. This technique plays an essential role in Paper $\mathrm{V}^{47}$ where the oxidation resistance of Ti-CrAl-N coatings was investigated.

\subsection{Nanoindentation}

Hardness is defined as the resistance against plastic deformation ${ }^{48}$ and nanoindentation is a method used to determine the hardness of thin films. A diamond tip is indented into the film while continuously observing the load and the displacement. The tip has a known contact area versus its penetration depth. If the tip leaves a plastic deformation not deeper than $\sim 10 \%$ of the coating thickness the deformation can be assumed to be independent of the substrate and the hardness of the coating can be determined as the force divided by the cross section area of the tip. 
When measuring the hardness of coatings that have been deposited using cathodic arc evaporation special care has to be taken to avoid areas containing the aforementioned macro particles. These residues from the deposition process impose defects in the lattice and will affect the mechanical properties in their vicinity. The coating surface is usually also relatively rough in comparison to the coating result of other deposition techniques such as sputtering. Therefore the surface has to be polished prior to measurement. To avoid complete removal of the coatings when the samples are polished they are mounted with a tampered angle in a sample holder to only partially remove the coating. The indentation sites are then carefully chosen using an optical microscope to avoid the micrometer sized particles. 


\subsection{Atom probe tomography}

Atom probe tomography allows for very precise quantification of the atomic concentrations and three dimensional reconstructions on an atomic scale. The samples have to be prepared and shaped into nanometer-sized tips using a focused ion beam instrument. Figure 8 shows the typical dimensions of the tip and how the reconstructed data may look like. During the experiment an electrical voltage is applied to the tip which is below the voltage required to evaporate species. Then an energetic laser beam shines onto the tip with a set frequency causing the material to evaporate preferably atom by atom. As the evaporated species are ejected they hit a detector measuring the spatial coordinates of the species in two dimensions. The time of flight is also recorded providing a mass to charge spectrum (acceleration voltage known). When combining this information the species may be identified and a three dimensional reconstruction on an atomic scale of the tip sample may be generated as the tip is evaporated. This technique was successfully applied in paper III to quantify the metallic concentrations within the different domains formed during the spinodal decomposition in Ti-Cr-Al-N coatings. 


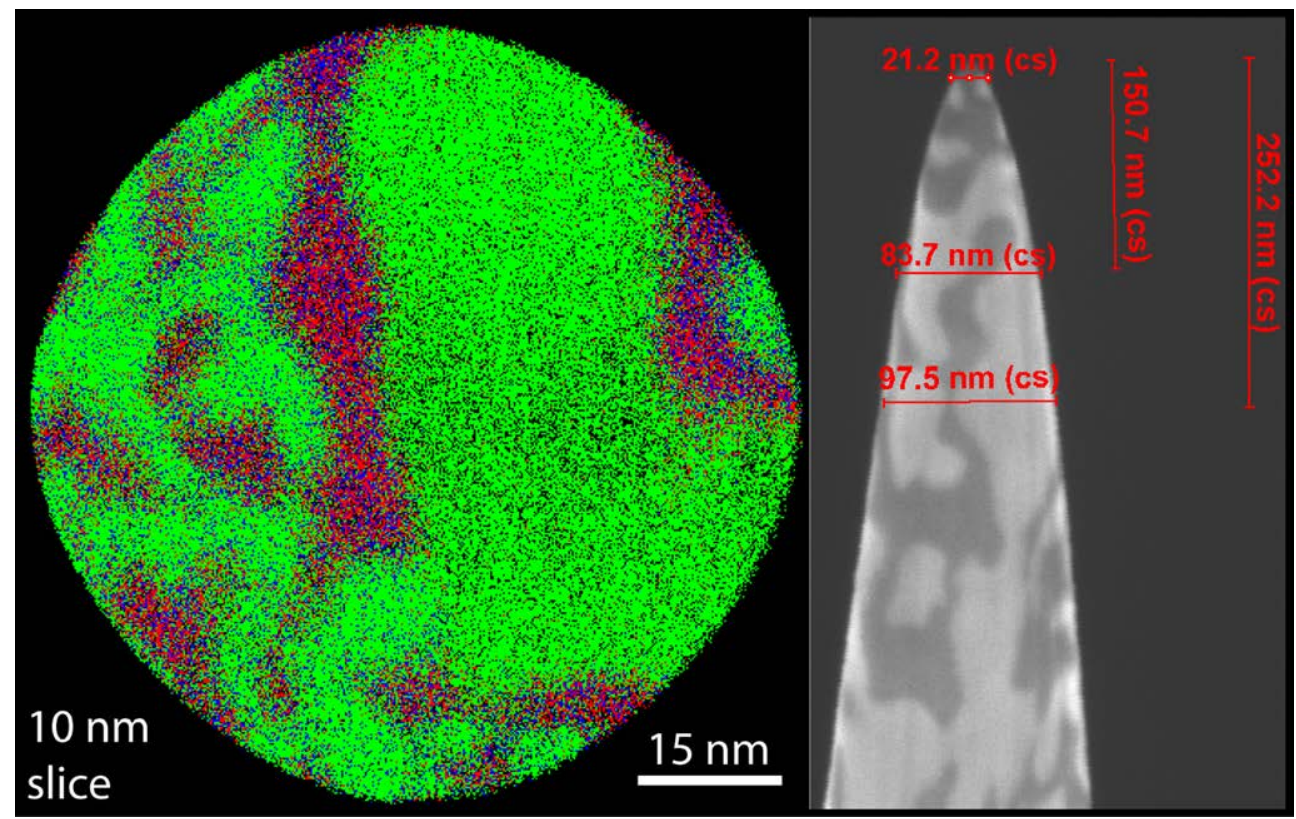

Figure 8 shows a color coded disc (10 nanometers thick) from a tip reconstruction (Al green, $\mathrm{Ti}$ red, $\mathrm{Cr}$ blue) of a Ti-Cr-Al-N coating annealed at $1100{ }^{\circ} \mathrm{C}$. The right side shows a SEM micrograph of the same material shaped as a tip using focused ion beam milling. I.C. Schramm is acknowledged for sample preparation and running the atom probe instrument. 


\section{Materials for hard nitride coatings}

In this work different compositions of different quaternary material systems have been deposited using the same deposition technique under fixed parameters. To deposit the coatings different combinations of compound cathodes have been used. Strictly speaking, different compositions of the cathodes may also influence the deposition parameters such as ion charge distributions, surface mobility and temperature. Different elements also evaporate more easily and at different rates with different angular distributions ${ }^{49}$. These effects have not been systematically investigated and are neglected in this work and the focus is on the yielded compositions as measured with energy dispersion $\mathrm{x}$-ray spectroscopy (EDX) and elastic recoil detection analysis (ERDA). All studied coatings in this work are quaternary nitrides containing different combinations of Ti-N, Cr-N, Zr-N and Al-N with a nitrogen content of $50 \pm 1 \%$. The ternary systems Ti-Al-N and Cr-Al-N are well studied and commonly used for cutting tool applications. Zr-Al-N is less studied but has been synthesized and studied many times before using cathodic arc evaporation. These ternary material systems have acted as references system during this work since they provide a good starting point of understanding the quaternary system. The studied quaternary systems may be considered as combinations of ternary material systems. Short summaries of the properties of these ternary systems are presented below. 


\subsection{Al-N based ternary coatings}

\subsubsection{Ti-Al-N}

Ti-Al-N has excellent mechanical properties at elevated temperatures and is widely used as a protective coating of cutting tools ${ }^{5,6}$. The mechanical properties and the oxidation resistance increase with higher $\mathrm{Al}$ content as long as a cubic structure can be maintained. But if the $\mathrm{Al}$ content is too high $h$ - $\mathrm{Al}-\mathrm{N}$ is formed and as a consequence the mechanical properties deteriorate. Therefore compositions close to $\operatorname{Ti}_{0.33} \mathrm{Al}_{0.67} \mathrm{~N}$ are typically used in order to avoid $h$-Al-N while optimizing the properties ${ }^{11,50}$. Al was added to the previously used Ti-N system with the intention to improve its poor oxidation resistance ${ }^{51,52}$. The great improvement of the mechanical properties when adding $\mathrm{Al}$ was initially attributed to the protective aluminum oxide layer formed at the surface of the coating ${ }^{5,6}$. The oxide layer at the surface acts as a barrier for the oxygen atoms to diffuse further into the coating and thus improving its mechanical properties ${ }^{53}$. This mechanism surely affects the mechanical properties in a positive way but nowadays it is not considered to be the major mechanism behind the improved properties and the observed age hardening in this material system. Instead the explanation can be found by studying the mixing free energy of $c$-Ti-Al-N which is positive and contains a spinodal meaning this is an unstable system. Based on this the $c$-Ti-Al-N system is predicted to transform into separate $c$-Ti-N and $c$-Al-N parts which is a more stable structure upon exposure to high temperatures. This is the mechanism behind the age hardening $9,11,12,13$. With around $70 \%$ of Al content the 
mixing free energy is close to its maximum within the spinodal. Thus any infinitesimal change in composition will lead to an overall decreased energy and therefore no nucleation site is required to initiate the segregation of Ti-N and Al-N. Upon exposure to high temperatures either during metal cutting or during annealing, the $\mathrm{Ti}$ and $\mathrm{Al}$ atoms begin to segregate while maintaining the cubic crystal structure. The result of the spinodal decomposition is coherent nanometer sized $c-\mathrm{Al}-\mathrm{N}-$ and $c$-Ti-N-enriched domains. This segregation is associated with strain due to the different elastic properties and the different lattice parameters of $c-\mathrm{Al}-\mathrm{N}$ and $c-\mathrm{Ti}-\mathrm{N}^{10,13}$ and because of this generated strain the propagation of dislocations is obstructed resulting in an increased hardness.

If the coating is continuously exposed to high temperatures a coarsening process takes place after the spinodal decomposition. During coarsening the energy is reduced by lowering the surface to volume ratio of the $c-\mathrm{Al}-\mathrm{N}$ and $c-\mathrm{Ti}-\mathrm{N}$ domains. When the domain interface becomes small in comparison to the domain size the coherency strain is relaxed by formation of dislocations. This is accompanied by a transformation of the $c$-Al-N into the more stable $h$-Al-N phase. These events lead to a dramatic decrease in hardness. ${ }^{37}$ Still Ti-Al-N coatings provide good abrasive wear protection of cutting tools. The decomposition route of Ti-Al-N can be expressed according the equation 4 .

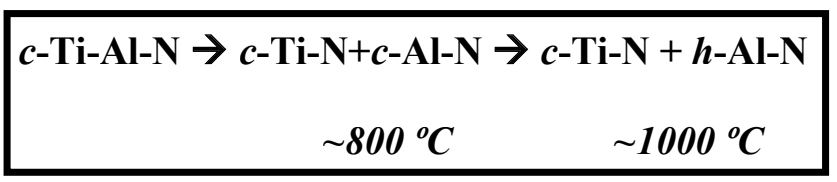

eq. 4 
For applications where the oxidation resistance is more important than the high temperature mechanical properties $\mathrm{Cr}-\mathrm{Al}-\mathrm{N}$ is a better choice compared to Ti-Al-N.

\subsubsection{Cr-Al-N}

$\mathrm{Cr}-\mathrm{N}$ coatings are widely used in plastic molding operations and metal forming to protect the tool from corrosion and oxidation. ${ }^{54}$ Just like what is done to improve the mechanical properties of Ti-N coatings, $\mathrm{Al}$ can be added to $\mathrm{Cr}-\mathrm{N}$ coatings forming a ternary system. ${ }^{55}$ With $\mathrm{Al}$ addition protective layers of chromium and aluminum oxide are formed at the coating surface preventing diffusion of oxygen deeper into the coating and in terms of corrosion and oxidation resistance $\mathrm{Cr}-\mathrm{Al}-\mathrm{N}$ coatings are superior to Ti-Al-N. ${ }^{28} c$-Cr-Al-N coatings can be deposited with up to $60-70$ at. $\%$ of Al. If the $\mathrm{Al}$ concentration is higher $h-\mathrm{Al}-\mathrm{N}$ will form and the hardness decreases. ${ }^{56,57}$ It has been reported that the cubic phase can be retained up to two hours of annealing at $900{ }^{\circ} \mathrm{C} .{ }^{56}$ Also, results from $\mathrm{Cr}_{0.32} \mathrm{Al}_{0.68} \mathrm{~N}^{29}$ coatings show a weak age hardening process ${ }^{11,12}$ due to Al-N precipitation at $\sim 700{ }^{\circ} \mathrm{C}$ but at higher temperatures the mechanical properties deteriorate. The high temperature mechanical properties are worse for Cr-Al-N compared to Ti-Al-N because the mixing free energy and the magnitude of its curvature are smaller compared to $c$-Ti-Al- $\mathrm{N}^{10,30}$. Thus when $c$-CrAl-N is exposed to high temperatures a coherent decomposition like for Ti-Al-N does not take place. ${ }^{29,58}$ The positive mixing free energy in the system results in formation and growth of $h$-Al-N precipitates in the vicinity of grain boundaries where the diffusion is high enough. When these $h$-Al-N precipitates grow the hardness is 
decreased rapidly at relatively low temperatures compared to Ti-Al-N. ${ }^{29,}{ }^{58}$ Since the temperature at the edge of a cutting tool during metal machining can reach beyond $1000{ }^{\circ} \mathrm{C}{ }^{59}, \mathrm{Cr}-\mathrm{Al}-\mathrm{N}$ protective coatings are inadequate for high temperature and high abrasive applications. The decomposition route of $\mathrm{Cr}-\mathrm{Al}-\mathrm{N}$ can be expressed according to equation 5 .

$c-\mathrm{Cr}-\mathrm{Al}-\mathrm{N} \rightarrow c-\mathrm{Cr}-\mathrm{Al}-\mathrm{N}+h-\mathrm{Al}-\mathrm{N}$ eq. 5 $\sim 700{ }^{\circ} \mathrm{C}$ 


\subsubsection{Zr-Al-N}

$c$-Zr-Al-N is an immiscible material system with the highest mixing free energy among the other material systems studied in this work ${ }^{60,61}$. The large positive mixing free energy is also accompanied by a large size mismatch between $c-\mathrm{Zr}-\mathrm{N}$ and metastable $c$-Al-N. The result of this is that the amount of $c$-Al-N that can be

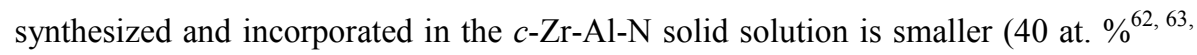

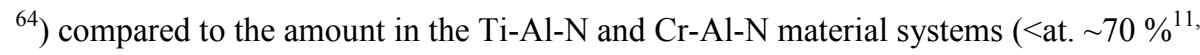
$50,56,58,64)$. If the Al-concentration is too high the structure becomes distorted containing cubic and hexagonal nano-crystallites and amorphous regions. This is detrimental for the hardness in the as deposited state whereas the nano-crystalline exhibit a significant age hardening effect due to crystallization of amorphous regions ${ }^{62}$, 65,66 


\subsection{Multicomponent alloying}

Thanks to the industrial scale deposition system that was used, it was quite straightforward and easy to deposit many different compositions within one deposition run. The cathodes were mounted vertically on the chamber wall and on opposite side the substrates were mounted on a rotating drum providing compositional gradients along the substrate column. Figure 9 shows the compositions of all the deposited monolith coatings in this work. Some compositions were determined using elastic recoil detection analysis (ERDA) but most of the compositions were determined using EDX. Because of the mass to charge overlaps between some isotopes of $\mathrm{Ti}$ and $\mathrm{Cr}$ EDX had to be used in order to quantify the concentrations of these two metallic elements. It is notable that none of the coatings have higher Al-content than $\sim 75 \%$. This is because of the low melting temperature of $\mathrm{Al}$ making it difficult to use pure $\mathrm{Al}$ cathodes for cathodic arc evaporation depositions. The coatings also become nonconductive with higher Al-concentrations making it impossible to keep a constant substrate bias since the flux of material is highly ionized ${ }^{46}$. All coatings were annealed after deposition at temperatures up to $1200{ }^{\circ} \mathrm{C}$ and quickly characterized with modern $\mathrm{XRD}$ and nanoindentation equipment. The results based on these techniques only give a fairly good overview and a hint of possible new candidates for improved hard coatings. The most interesting compositional regions were later on chosen for more detailed analysis of the mechanisms that lie behind the hardness and the thermal phase stability. Only short summaries of the results are given here, more detailed results and 
discussions are presented in the attached papers and may also be found in the two master theses that I supervised (see introduction for details).

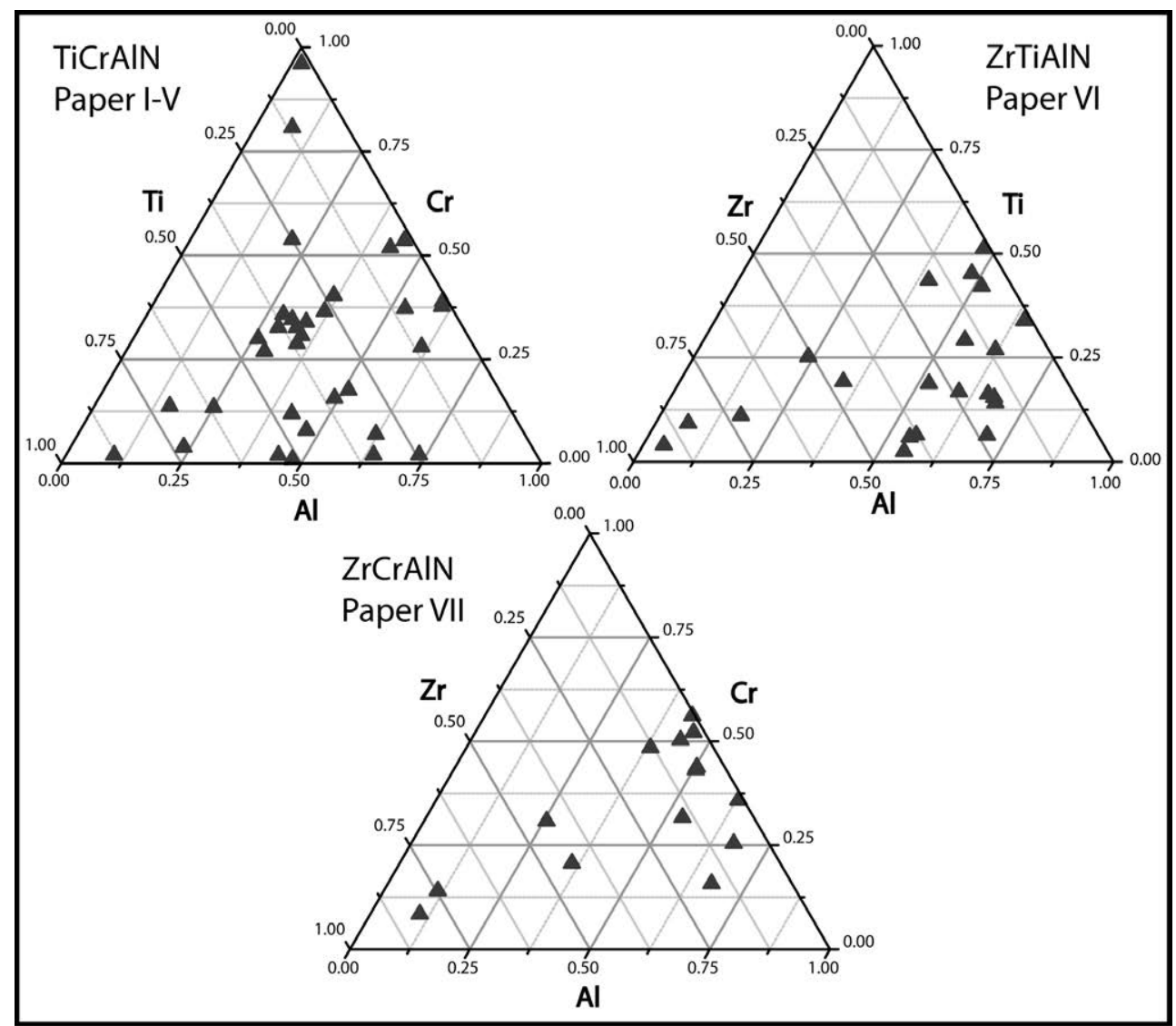

Figure 9 shows three ternary plots of the deposited coatings in this work. The material systems that have been studied are Ti-Cr-Al-N, Ti-Zr-Al-N and Zr-Cr-Al-N. 


\subsubsection{Ti-Cr-Al-N}

Ti-Cr-Al-N is a commercially available material system used for protective coatings of cutting tools. Various studies have shown that the performance of these coatings may outperform Ti-Al-N coatings ${ }^{24-27,67}$. The fundamental mechanisms that yield these enhanced properties were not understood at the beginning of this work. The theoretical work was conducted in collaboration with the theoretical physics group at IFM and presented in paper $\mathrm{I}^{30}$ and VI. Instead of using super-cell calculations the mixing free energy are based on a mean field potential approximations ${ }^{9}$. Figure 10 (a) shows the mixing free energy (left) and the magnitude of the second derivative of the mixing free energy (right) at $1300 \mathrm{~K}$ where the arrows point towards the direction where the driving force is highest. Figure 10 (b) shows the hardness measured versus the annealing temperature for two Ti-Cr-Al-N coatings. Between 1000 and $1100{ }^{\circ} \mathrm{C}$ the hardness is significantly higher compared to Ti-Al-N coatings. Figure 10 (c) shows xray diffractograms obtained from the same samples depicting cubic peaks from solid solution Ti-Cr-Al-N peaks. Thanks to the $\mathrm{Cr}$ addition the cubic structure is stable up to high temperatures of 1000 to $1100^{\circ} \mathrm{C}$. With increasing Cr-content, $17 \%$ (black curve), the cubic structure is more stable because the lower driving force for spinodal decomposition delays the coarsening process generating smaller $\mathrm{TiCr}-$ and $\mathrm{Al}$ enriched domain sizes which are more stable.

The most important result is that Ti-Cr-Al-N coatings decompose via an intermediate metastable phase, $c$-Cr-Al-N, before the $c$-Al-N phase transforms into $h$-Al-N. The result is a retained hardness at higher temperatures compared to Ti-Al-N coatings. 


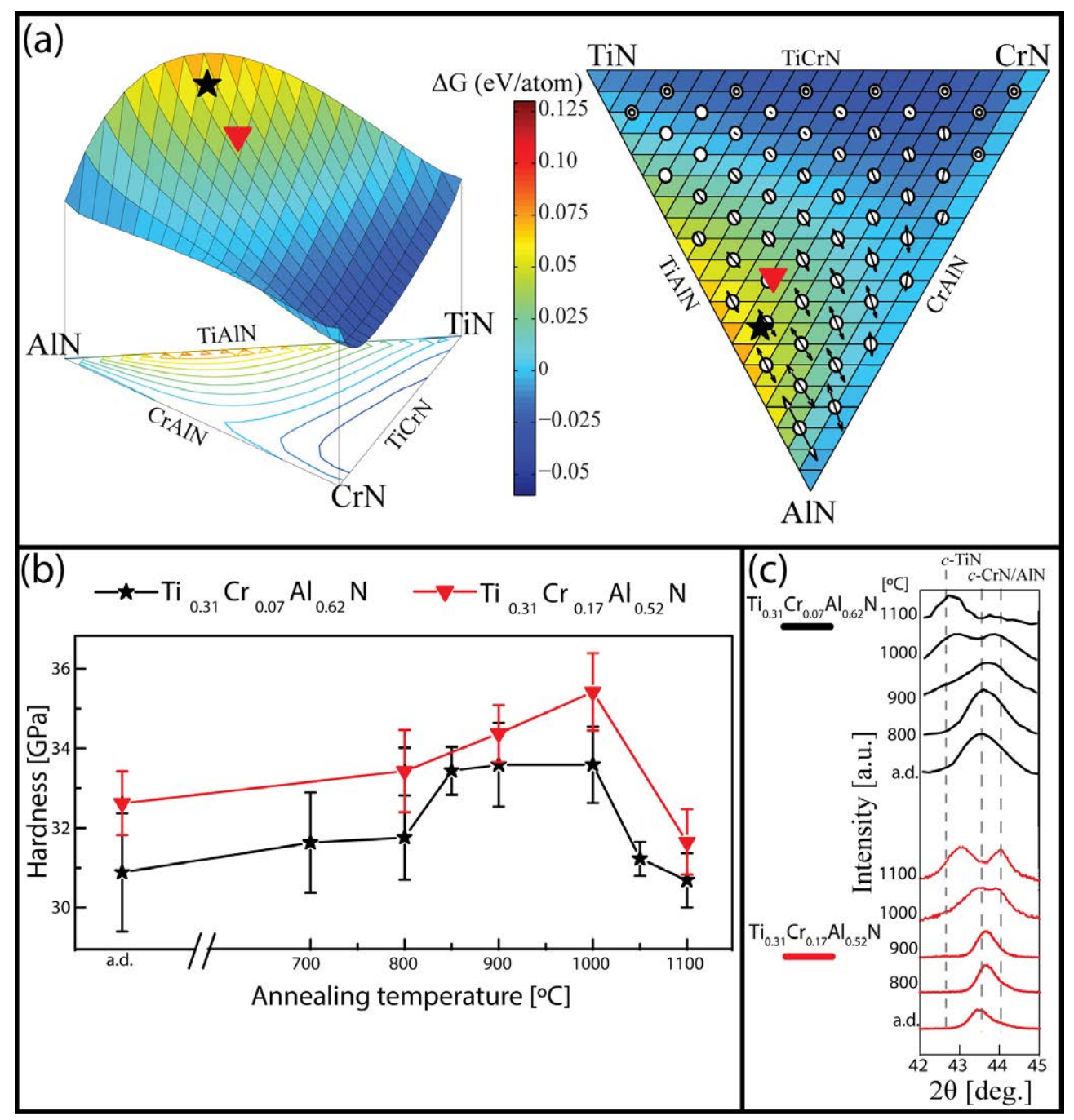

Figure 10 (a) shows the mixing free energy (left) and driving force for spinodal decomposition (right) in $c$-Ti-Cr-Al- $\mathrm{N}^{30}$ both at $1300 \mathrm{~K}$. (b) Hardness versus annealing temperature. (c) $\mathrm{x}$-ray diffractograms depicting cubic peaks at different annealing temperatures ${ }^{68}$. 


\subsubsection{Ti-Zr-Al-N}

Figure 11 (a) shows the calculated mixing free energy of the Ti-Zr-Al-N system at $1000{ }^{\circ} \mathrm{C}$. It is seen that the mixing free energy is positive meaning that the system is unstable. The mixing free energy is much higher along the Zr-Al-N ternary compared to Ti-Al-N. The right part shows the direction and relative magnitude of the driving force for spinodal decomposition. It is seen that no spinodal decomposition is expected for very high Zr-contents but with lower Zr-content there is a tendency for separation between $\mathrm{Al}$ and $\mathrm{Zr}$ through spinodal decomposition. These results were also experimentally confirmed. Figure 11 (b) contains hardness results plotted versus the annealing temperature. It is seen that coatings with high $\mathrm{Zr}$-contens do not show any age hardening due to the lack of spinodal decomposition. Instead the hardness decreases due to crystal recovery and stress relaxation. For composition within the spinodal the hardness increases upon annealing due to coherency strain generated during the decomposition and due to crystallization of amorphous regions generated by the large size mismatch between $\mathrm{ZrN}$ and AlN. Figure 11 (c) shows XRD diffractograms for one sample where the driving force for spinodal decomposition is low (top) where the cubic structure is stable and one sample within the spinodal (lower) where the cubic peak (200) broadens due to the decomposition of the structure. More experimental results may be found in paper VI where similar coatings were deposited and analyzed with STEM. 


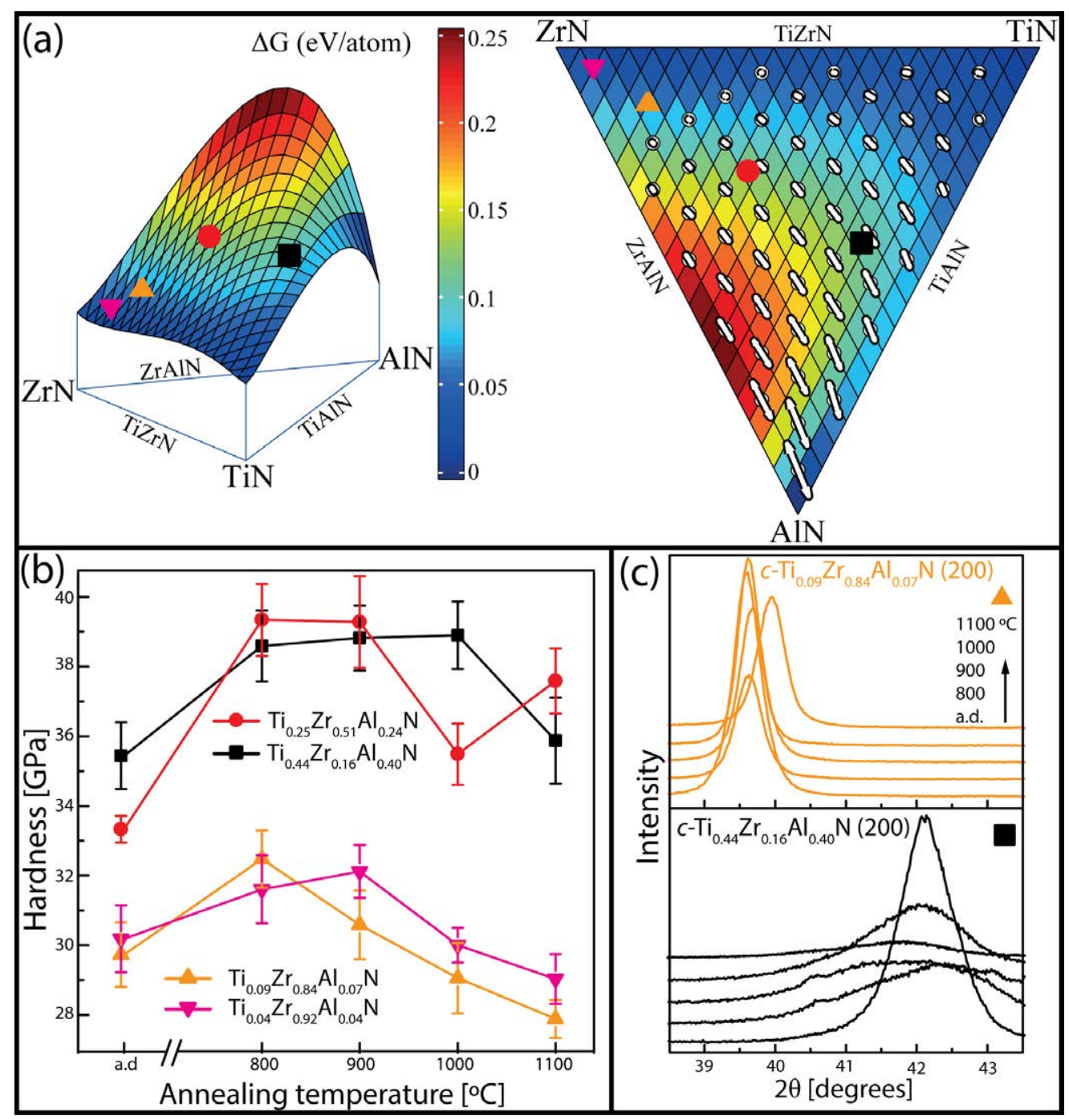

Figure 11 (a) shows the mixing free energy (left) and driving force for spinodal decomposition (right) in $c$-Ti-Zr-Al-N [Paper VI] both at $1000{ }^{\circ} \mathrm{C}$. (b) Hardness versus annealing temperature of the two unstable $c$-Ti-Zr-Al-N coatings marked in the energy plots. (c) $\mathrm{x}$-ray diffractograms depicting cubic peaks in the same coatings at different annealing temperatures [Unpublished results]. 


\subsubsection{Cr-Zr-Al-N}

The mean field potential approximation used to successfully calculate mixing free energy for the other two quaternary material systems fails to provide reliable results for the Cr-Zr-Al-N. The reason is that the Madelung constants (the screening effect of the electrical charge) for the $\mathrm{Cr}$ and $\mathrm{Zr}$ component cannot be approximated to be equal. To calculate the mixing free energy would require knowledge of screening effect as a function of the composition or the use of a more fundamental approach such as supercell constructions.

The industrial scale deposition system allows depositing coatings covering almost the entire metal ternary. Furthermore, with the aid of a fast and efficient XRD setup the structure of all the coatings may be characterized. Most results are submitted for publication and may be found in paper VII. The background for this work is that useful coatings should have a mixing free energy large enough to generate age hardening. But the mixing free energy should also be small enough to allow for depositing unstable cubic solid solutions. Zr-Cr-Al-N coatings were deposited because within this system it is possible to alloy components with significantly different mixing free energies and size mismatches.

Figure 12 shows the hardness versus annealing temperature and basically gives a broad summary of the results from this work. The coatings have been grouped in three different categories. The first category of coatings (green), $(\mathrm{Al}<\sim 30$ at. $\%$ and $\sim 40$ at. $\%<\mathrm{Zr}$ ), are stable cubic solid solutions up to $1100^{\circ} \mathrm{C}$. The hardness decreases upon annealing because of defect annihilation. In the second category (orange), $(40<\mathrm{Al}<$ 
60 and $\mathrm{Zr}<15)$, the coatings decompose into $\mathrm{ZrCr}$ - and Al-rich nanometer-sized domains upon annealing generating a hardness increase. In the third category (red) $(\sim 67<\mathrm{Al})$, the microstructure contain a mixture of amorphous and 1-2 nanometersized nanocrystalline hexagonal (Al-N) and cubic $(\mathrm{Zr}-\mathrm{Cr}-\mathrm{N})$ phases. These coatings have a significantly lower hardness in the as deposited state. Upon annealing, the hardness increases due to crystallization of the amorphous regions.

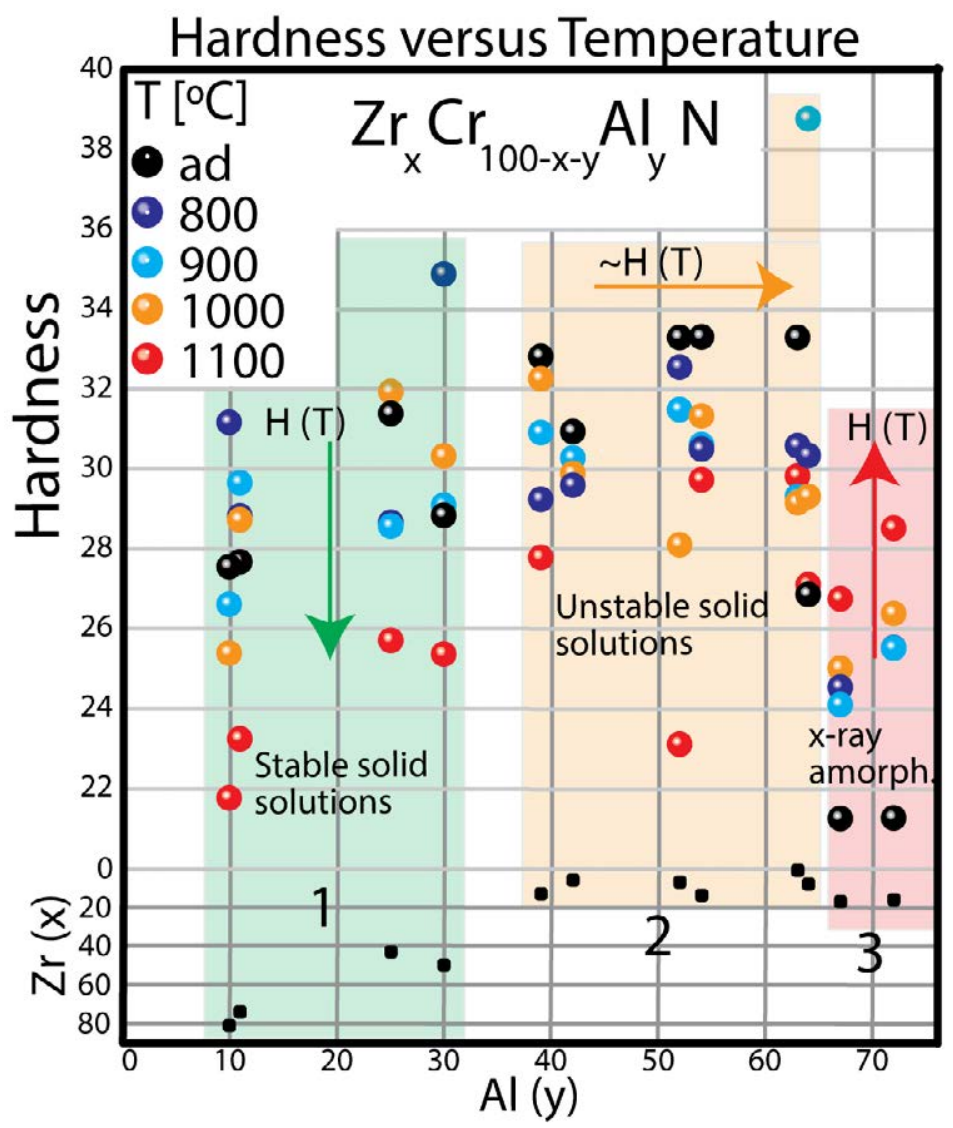

Figure 12 shows hardness versus annealing temperature of different $\mathrm{Zr}$-Cr-Al-N coatings divided into three different categories. 


\subsection{Multilayer multicomponent alloying}

Multilayer coatings may provide a scientist ways to study and isolate a phenomenon at nanometer- or atomic scales. One example highly relevant for this thesis is the study of the effect of coherency strain on the stability of the $c$-Al-N phase ${ }^{69,70}$. In many other investigations multilayer concepts have been applied in order to improve the thermal stability and the hardness over single layer coatings ${ }^{69,71,72,73}$. Most relevant studies for this work are Ti-Al-N/Ti-N multilayer coatings exhibiting higher hardness compared to the Ti-Al-N coating at high annealing temperatures ${ }^{7,8,23}$. Paper IV $^{74}$ deals with cubic coherent Ti-Cr-Al-N/Ti-Cr-N multilayer coatings as depicted in the (S)TEM micrographs in Figures 13 and 14.

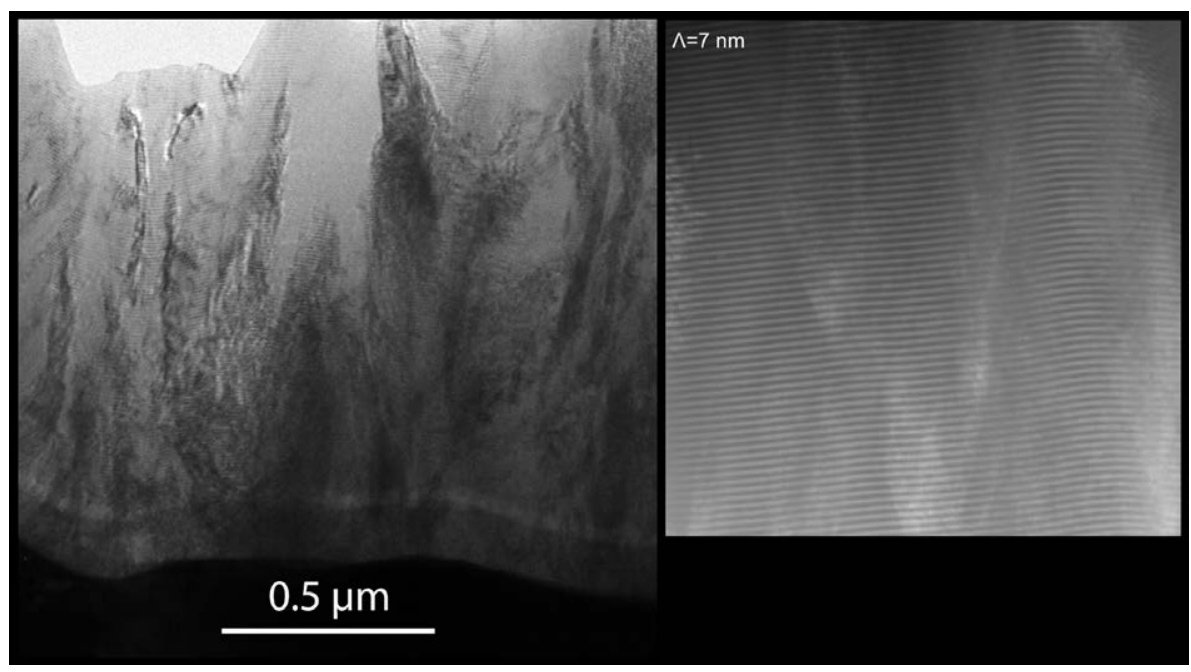

Figure 13 shows a TEM diffraction contrast overview micrograph (left) and a Z-contrast STEM micrograph (right) depicting the multilayer structure. 


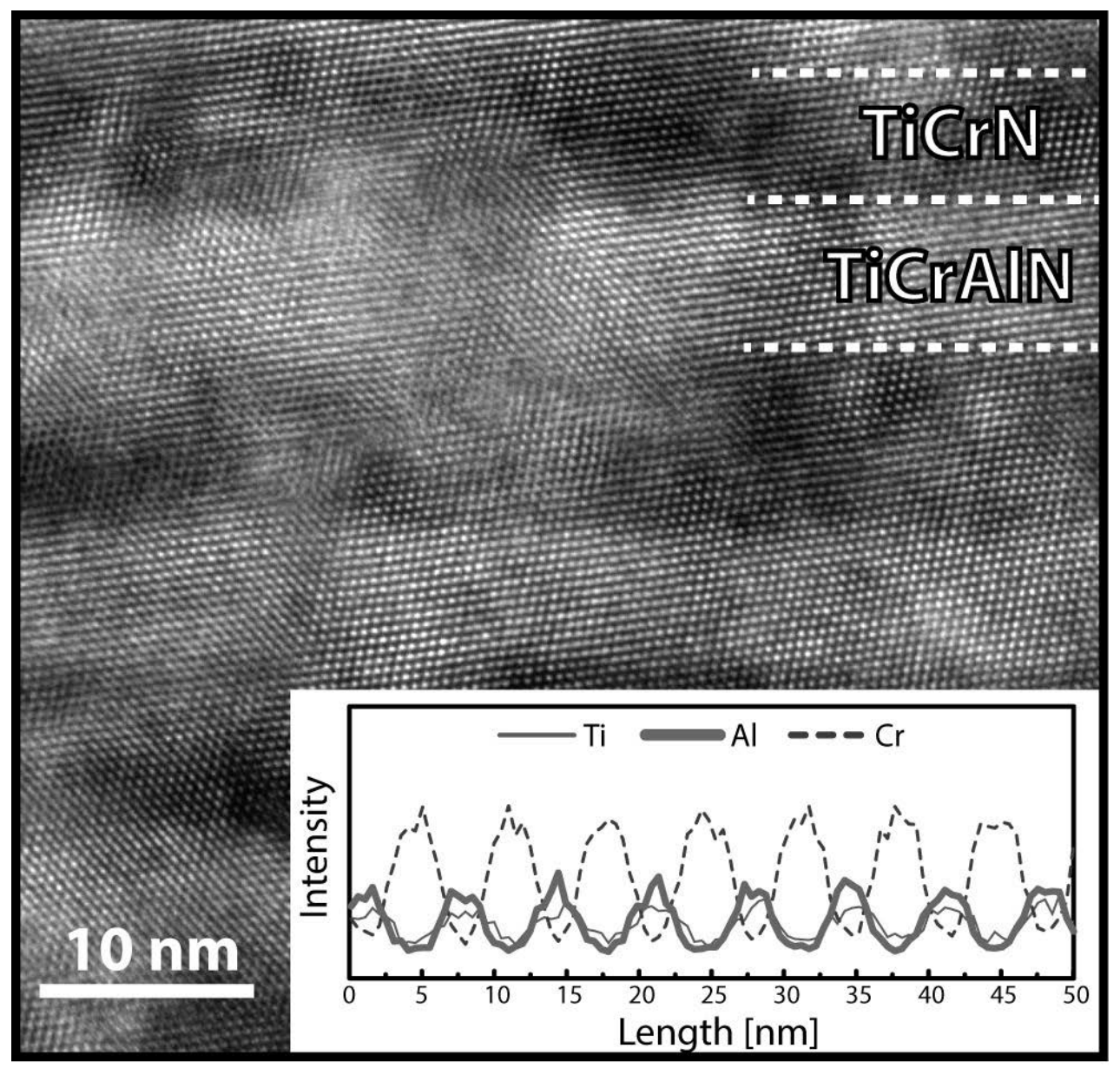

Figure 14 shows a TEM lattice resolved micrograph depicting a cubic coherent multilayer structure. The insets shows an EDX line scan obtained across the layers. 
The benefits of multicomponent alloying and the benefits of multilayer coating architectures were combined and successfully utilized to generate improved hardness at high annealing temperatures. Figure 15 shows the hardness versus annealing temperature of different Ti-Cr-Al-N $/ \mathrm{Ti}_{1-\mathrm{x}}-\mathrm{Cr}_{\mathrm{x}}-\mathrm{N}$ multilayer coatings (period $\sim 8 \mathrm{~nm}$ ) where the composition (x) was changed to generate coatings with different lattice parameter mismatches. It can be seen that the hardness is higher for the coatings with higher mismatch due to the hardening effect of the coherency strain fields ${ }^{72,75,76}$.

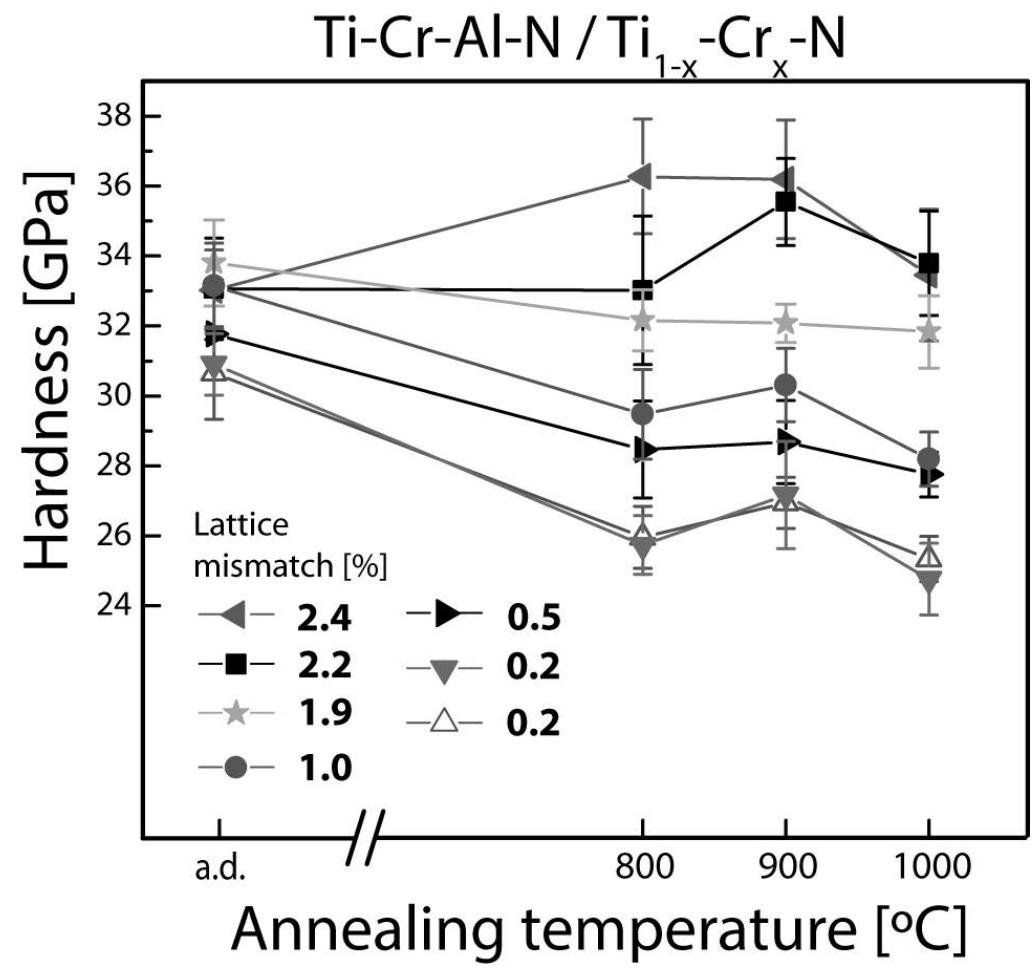

Figure 15 shows hardness versus annealing temperatures for different multilayer coatings with varying lattice parameter mismatches. 
It is seen that the hardness is improved at annealing temperatures between 800 and $1000{ }^{\circ} \mathrm{C}$ over the corresponding monolith coating as seen in Figure 16.

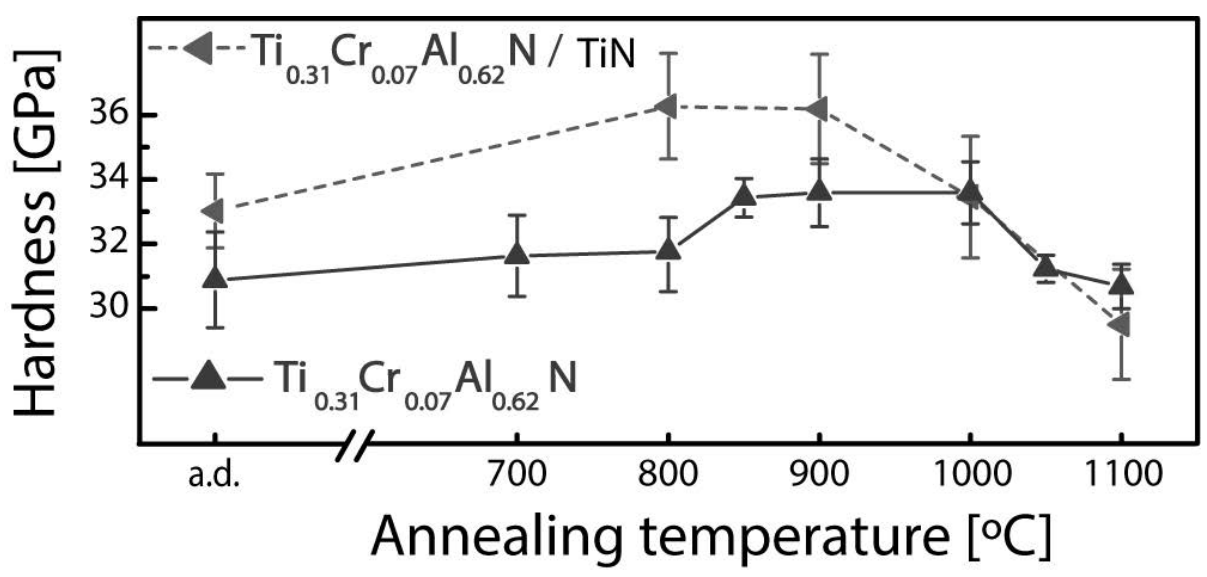

Figure 16 shows the hardness versus annealing temperature of a Ti-Cr-Al-N monolith coating compared with the hardness of the same coating layered with Ti-N (period: $8 \mathrm{~nm}$ ). 


\section{Scientific output}

Here follows short summaries of the scientific results in each of the attached papers.

\subsection{Summaries of the included papers Paper I}

Improving thermal stability of hard coating films via a concept of multicomponent alloying

The mixing free energy and the driving force for spinodal decomposition in $c$-Ti-CrAl-N is calculated based on first principle calculations. The mixing free energy depends on the metallic concentrations and is more sensitive to the Al-content. Along the Ti-Al-N ternary the mixing free energy is the highest with a spinodal region extending over almost all compositions except close to the binaries (Ti-N and Al-N). Cr-Al-N also has a positive mixing free energy but with much lower curvature. For Ti$\mathrm{Cr}-\mathrm{N}$ the mixing free energy is more or less zero. This paper investigates and predicts the decomposition products and routes of low $\mathrm{Cr}$-containing Ti-Cr-Al-N coatings. The coatings decompose into cubic and coherent $\mathrm{TiCr}-$ and Al-enriched Ti-Cr-Al-N domains. The most striking result is that the decomposition takes place via the metastable $c$-Cr-Al-N phase. It is shown that because of this intermediate step in the decomposition route the thermal stability of the cubic structure and the hardness is improved compared to Ti-Al-N coatings. 


\section{Paper II}

Decomposition and phase transformation in TiCrAlN thin coatings

In this paper a more detailed experimental verification, an extension of the studied compositions $\left(\mathrm{Cr}\right.$-content $<17$ at. \%) and higher annealing temperatures $\left(1400{ }^{\circ} \mathrm{C}\right)$ compared to the results in paper I are presented. It is highlighted that since the lattice parameter of $\mathrm{Cr}-\mathrm{N}$ lies in between Ti-N and Al-N the driving force for relaxation of the coherent domain boundaries is reduced during the decomposition. This results in a less pronounced age hardening but also in a retained hardness at higher temperatures since the domains remain coherent. The decomposition route of Ti-Cr-Al-N coatings follows the following route: $c$-Ti-Cr-Al-N $\rightarrow c$-Ti-Cr-N $+c$-Cr-Al-N $\rightarrow c$-Ti-Cr-N + $h$-Al-N $\rightarrow c-\mathrm{Ti}-\mathrm{N}+\beta-\mathrm{Cr}_{2} \mathrm{~N}+h-\mathrm{Al}-\mathrm{N} \rightarrow c-\mathrm{Ti}-\mathrm{N}+b c c-\mathrm{Cr}+h$-Al-N up to annealing temperatures of $1400{ }^{\circ} \mathrm{C}$. It is verified that the driving force for spinodal decomposition is lowered with increasing $\mathrm{Cr}$ content. Higher $\mathrm{Cr}$-content results in increased time duration for the compositional amplitude to develop during the spinodal decomposition which delays the onset of the coarsening. Because of the delayed coarsening the domain boundaries are maintained coherent at even higher temperatures resulting in higher hardness at temperatures of $1000-1100{ }^{\circ} \mathrm{C}$. It is also shown that by increasing the $\mathrm{Cr}$ content $(<17$ at. \%) formation of $h$-Al-N precipitates in grain boundaries is promoted over the competing spinodal decomposition process. 


\section{Paper III}

Nanostructuring and coherency strain in multicomponent hard coatings

This paper deals with the same solid solution cubic $\mathrm{Ti}_{0.31} \mathrm{Cr}_{0.17} \mathrm{Al}_{0.52} \mathrm{~N}$ coating that was presented in paper II. The coating was annealed at temperatures of 1000 and $1100{ }^{\circ} \mathrm{C}$. The results here completely rely on the high resolution micrograph obtained with a state of the art double corrected transmission electron microscope and the metallic concentration quantification performed with a local electrode atom probe microscope. As shown previously, at $1000{ }^{\circ} \mathrm{C}$, the coating has undergone spinodal decomposition into $\sim 5$ nanometer-sized coherent cubic TiCr- and Al-rich phases. Here it is observed that, at $1100{ }^{\circ} \mathrm{C}$, in the phases where $\mathrm{Cr}$ atoms are present the structure is cubic and where $\mathrm{Cr}$ atoms are absent the structure has transformed from cubic to hexagonal. The local metallic concentrations of the phases and at the interfaces have been quantified and it is concluded that the metastable cubic $\mathrm{Al}(\mathrm{Cr})-\mathrm{N}$ phase contains $9 \% \mathrm{Cr}$. It is further concluded that the coherency strain between the phases are not fully relaxed since the hexagonal phases are semi-coherent with the cubic phases. 


\section{Paper IV}

Coherency strain engineered decomposition of unstable multilayer alloys for improved thermal stability

In this work $\mathrm{Ti}-\mathrm{Cr}-\mathrm{Al}-\mathrm{N} / \mathrm{Ti}_{1-\mathrm{x}} \mathrm{Cr}_{\mathrm{x}} \mathrm{N}$ multilayer coatings have been investigated. $\mathrm{A}$ concept to improve the hardness and thermal stability of unstable multilayer alloys is presented based on control of the coherency strain such that the driving force for decomposition is favorably altered. Upon annealing, these multilayer coatings undergo spinodal decomposition into nanometer-sized coherent Ti- and Al-rich cubic domains. The diffusion of the metallic elements during the decomposition is affected by the coherency strain where it occurs iso-tropically with higher strain and predominantly parallel to the growth direction with lower strain. In addition, the growth of the domains is restricted by the surrounding Ti-Cr-N layer compared the non-layered TiCr-Al-N coatings. The multilayer structure results in an improved thermal stability of the cubic structure. A significant hardness increase is seen during decomposition for the case with high coherency strain while a low coherency strain results in a hardness decrease for high annealing temperatures. 


\section{Paper V}

Effects of Ti alloying of AlCrN coatings on thermal stability and oxidation resistance

This paper extends the investigations of Ti-Cr-Al-N coatings to higher Cr-containing coatings. To better understand the results and to closer match with the compositions studied in this paper the previous reference material system, Ti-Al-N, is changed to $\mathrm{Cr}-$ Al-N. Therefore the paper may be summarized as a study of the influence of Ti addition to Cr-Al-N in terms of thermal stability of the cubic structure and the hardness. Because of the superior oxidation resistance of Cr-Al-N coatings compared to Ti-Al-N system it is also makes sense to study the how the oxidation resistance is affected by the addition of Ti. The results show that the hardness of Cr-Al-N coatings is drastically improved through the $\mathrm{Ti}$ addition. The decomposition of low Ticontaining Ti-Cr-Al-N coatings takes place via a combination of a nucleation and growth process of $h$-Al-N precipitates in the grain boundaries and spinodal decomposition into TiCr- and Al-enriched domains in the grain interiors. The Ti addition suppresses and delays the formation and growth of the detrimental the $h$-Al-N resulting in improved hardness compared to ternary Cr-Al-N coatings. The oxidation resistance is negatively affected by the $\mathrm{Ti}$ addition due the promotion of a $\mathrm{TiO}_{2}$ surface layer over the more protective $\alpha-\mathrm{Al}_{2} \mathrm{O}_{3}$. The most striking result is that it is possible to generate coatings that outperform ternary Ti-Al-N in terms of both oxidation resistance and mechanical properties at elevated temperatures. 


\section{Paper VI}

High temperature phase decomposition in $\mathrm{Ti}_{x} \mathrm{Zr}_{y} \mathrm{Al}_{z} \mathrm{~N}$

Using a combination of theoretical and experimental observations the high temperature decomposition behavior of Ti-Zr-Al-N coatings are studied. The high mixing free energy in these coatings generates a strong driving force for spinodal decomposition between Zr-N and Al-N in Zr-poor coatings and while Zr-rich coatings shows a greatly reduced decomposition rate. The theoretical results highlight the importance of considering the second derivative of the free energy, in addition to its absolute value in predicting decomposition trends of thermodynamically unstable alloys. 


\section{Paper VII}

Alloying as a tool for structure and thermal stability engineering of hard coatings

This work illustrates how the structure and hardness of unstable multicomponent alloy may be controlled and altered via the mixing free energy between the alloyed components. Cubic Zr-Cr-Al-N coatings have been chosen as a model system offering components of different degrees of miscibility and sizes. The coatings have been divided into three different compositional categories where the coatings exhibit different microstructure, thermal stability and hardness depending on the driving force for decomposition.

The first category of coatings, $(\mathrm{Al}<\sim 30 \%$ and $\sim 40 \%<\mathrm{Zr}$ ), are stable cubic solid solutions up to $1100{ }^{\circ} \mathrm{C}$. The hardness decreases upon annealing because of defect annihilation. In the second category, $(40 \%<\mathrm{Al}<60 \%$ and $\mathrm{Zr}<15 \%)$, the coatings decompose into $\mathrm{ZrCr}$ - and Al-rich nanometer-sized domains when annealed, which results in a hardness increase. In the third category $(\sim 67 \%<\mathrm{Al})$, the microstructure contain a mixture of 1-2 nanometer-sized nano-crystalline hexagonal (Al-N) and cubic (Zr-Cr-N) phases. These coatings have a significantly lower hardness in the as deposited state but upon annealing the hardness increases significantly.

Altogether it is shown that a possible mean to design new functional hard coatings with high hardness at elevated is to fine-tune the composition close to the deposition limit for cubic solid solution while avoiding formation of nano-crystalline structures. 


\section{References}

1 L. Martinu, and D. Poitras, J. Vac. Sci. Technol. A 18, 6 (2000).

2 P. H. Mayrhofer, C. Mitterer, L. Hultman, and H. Clemens, Prog. Mater. Sci. 51, 8 (2006a).

3 T. Childs, Metal Machining : Theory and Applications,_(Arnold, London, 2000).

4 Modern Skärande Bearbetning : En Praktisk Handbok, 1. svenska utg. ed. (Sandvik Coromant, Sandviken, 1995).

5 O. Knotek, M. Bohmer, and T. Leyendecker, J.Vac.Sci.Technol.A 4, 6 , Nov.-Dec. 1986 (1986).

6 H. A. Jehn, S. Hofmann, V. Ruckborn, and W. Munz, J. Vac. Sci. Technol. A 4, 6 (1986).

7 A. Knutsson, M. P. Johansson, P. O. Å Persson, L. Hultman, and M. Odén, Appl. Phys. Lett. 93, 14 (2008).

8 A. Knutsson, M. P. Johansson, L. Karlsson, and M. Odén, J. Appl. Phys. 108, 4 (2010).

9 B. Alling, A. V. Ruban, A. Karimi, O. E. Peil, S. I. Simak, L. Hultman, and I. A. Abrikosov, Phys. Rev. B 75, 4 (2007a).

10 B. Alling, T. Marten, I. A. Abrikosov, and A. Karimi, J. Appl. Phys. 102, 4 (2007b).

11 A. Hörling, L. Hultman, M. Odén, J. Sjölén, and L. Karlsson, J. Vac. Sci. Technol. A 20, 5 (2002).

12 A. Hörling, L. Hultman, M. Odén, J. Sjölén, and L. Karlsson, Surf. Coat. Technol. 191, 2-3 (2005).

13 P. H. Mayrhofer, A. Hörling, L. Karlsson, J. Sjölén, T. Larsson, C. Mitterer, and L. Hultman, Appl. Phys. Lett. 83, 10 (2003).

14 R. M'Saoubi, C. Le Calvez, B. Changeux, and J. L. Lebrun, Proc. Inst. Mech. Eng. Pt. B: J. Eng. Manuf. 216, 2 (2002). 
15 M. A. Davies, T. Ueda, R. M'Saoubi, B. Mullany, and A. L. Cooke, CIRP Ann. Manuf. Technol. 56, 2 (2007).

16 D. Holec, F. Rovere, P. H. Mayrhofer, and P. B. Barna, Scr. Mater. 62, 6 (2010).

17 N. Norrby, L. Rogström, M. P. Johansson-Jõesaar, N. Schell, and M. Odén, Acta Mater. 73, (2014).

18 N. Norrby, H. Lind, G. Parakhonskiy, M. P. Johansson, F. Tasnádi, L. S. Dubrovinsky, N. Dubrovinskaia, I. A. Abrikosov, and M. Odén, J. Appl. Phys. 113, 5 (2013).

19 L. Rogström, J. Ullbrand, J. Almer, L. Hultman, B. Jansson, and M. Odén, Thin Solid Films 520, 17 (2012a).

20 M. P. Johansson Jöesaar, N. Norrby, J. Ullbrand, R. M'Saoubi, and M. Odén, Surf. Coat. Technol. 235, 0 (2013).

21 R. Rachbauer, D. Holec, M. Lattemann, L. Hultman, and P. H. Mayrhofer, Int. J. Mater. Res. 102, 6 (2011).

22 K. Kutschej, N. Fateh, P. H. Mayrhofer, M. Kathrein, P. Polcik, and C. Mitterer, Surf. Coat. Technol. 200, 1-4 (2005).

23 A. Knutsson, M. P. Johansson, L. Karlsson, and M. Odén, Surf. Coat. Technol. 205, $16(2011)$.

24 S. G. Harris, E. D. Doyle, A. C. Vlasveld, J. Audy, J. M. Long, and D. Quick, Wear 254, 1-2 (2003).

25 Z. F. Zhou, P. L. Tam, P. W. Shum, and K. Y. Li, Thin Solid Films 517, 17 (2009).

26 A. I. Kovalev, D. L. Wainstein, A. Y. Rashkovskiy, G. S. Fox-Rabinovich, K. Yamamoto, S. Veldhuis, M. Aguirre, and B. D. Beake, Vacuum 84, 1 (2009).

27 Y. X. Xu, L. Chen, B. Yang, Y. B. Peng, Y. Du, J. C. Feng, and F. Pei, Surf. Coat. Technol. 235, 0 (2013).

28 M. Kawate, A. K. Hashimoto, and T. Suzuki, Surf. Coat. Technol. 165, 2 (2003).

29 H. Willmann, P. H. Mayrhofer, L. Hultman, and C. Mitterer, J. Mater. Res. 23, 11 (2008). 
30 H. Lind, R. Forsén, B. Alling, N. Ghafoor, F. Tasnádi, M. P. Johansson, I. A. Abrikosov, and M. Odén, Appl. Phys. Lett. 99, 9 (2011).

31 C. John W, Acta Mater. 9, 9 (1961).

32 M. Hillert, Acta Metallurgica 9, 6 (1961).

33 L. Karlsson, L. Hultman, and J. -. Sundgren, Thin Solid Films 371, 1 (2000).

34 P. H. Mayrhofer, G. Tischler, and C. Mitterer, Surface and Coatings Technology 142-144, (2001).

35 P. H. Mayrhofer, C. Mitterer, L. Hultman, and H. Clemens, Prog. Mater. Sci. 51, 8 (2006b).

36 L. Karlsson, A. Hörling, M. P. Johansson, L. Hultman, and G. Ramanath, Acta Materialia 50, 20 (2002).

37 M. Odén, L. Rogström, A. Knutsson, M. R. Terner, P. Hedström, J. Almer, and J. Ilavsky, Appl. Phys. Lett. 94, 5 (2009).

38 Handbook of Deposition Technologies for Films and Coatings : Science, Technology and Applications, 2. ed. ed. (Noyes, Park Ridge, N.J., 1994).

39 S. M. Rossnagel, J. Vac. Sci. Technol. B 16, 5 (1998).

40 J. Vyskocil, and J. Musil, Cathodic Arc Evaporation in Thin Film Technology, (AVS, 1992), p. 1740.

41 V. Kouznetsov, K. Macák, J. M. Schneider, U. Helmersson, and I. Petrov, Surf. Coat. Technol. 122, 2-3 (1999).

42 U. Helmersson, M. Lattemann, J. Bohlmark, A. P. Ehiasarian, and J. T. Gudmundsson, Thin Solid Films 513, 1-2 (2006).

43 D. M. Mattox, Met Finish 100, 1 SUPPL. (2002).

44 I. G. Brown, Annual Review of Materials Science 28, 1 (1998).

45 M. A. Lieberman, and A. J. Lichtenberg, Principles of Plasma Discharges and Materials Processing, (John Wiley \& Sons, 2005). 
46 K. Bouzakis, N. Michailidis, G. Skordaris, E. Bouzakis, D. Biermann, and R. M'Saoubi, CIRP Ann. Manuf. Technol. 61, 2 (2012).

47 R. Forsén, M. P. Johansson, M. Odén, and N. Ghafoor, Thin Solid Films 534, (2013).

48 ASM Handbook. Vol. 8, Mechanical Testing and Evaluation, Rev. ed. ed. (ASM International, Materials Park, Ohio, 2000).

49 A. O. Eriksson, J. Q. Zhu, N. Ghafoor, M. P. Johansson, J. Sjölen, J. Jensen, M. Odén, L. Hultman, and J. Rosén, Surf. Coat. Technol. 205, 15 (2011).

50 M. Zhou, Y. Makino, M. Nose, and K. Nogi, Thin Solid Films 339, 1-2 (1999).

51 B. Navinšek, P. Panjan, and A. Cvelbar, Surf. Coat. Technol. 74-75, PART 1 (1995).

52 J. C. Knight, Wear 138, 1-2 (1990).

53 B. Kim, Y. Kim, J. Nah, and J. Lee, J. Vac. Sci. Technol. A 17, 1 (1999).

54 J. Vetter, Surf. Coat. Technol. 76-77, PART 2 (1995).

55 O. Knotek, M. Atzor, A. Barimani, and F. Jungblut, Surf. Coat. Technol. 42, 1 (1990).

56 A. E. Reiter, V. H. Derflinger, B. Hanselmann, T. Bachmann, and B. Sartory, Surf. Coat. Technol. 200, 7 (2005).

57 H. Hasegawa, and T. Suzuki, Surf. Coat. Technol. 188-189, 1-3 SPEC.ISS. (2004).

58 H. Willmann, P. H. Mayrhofer, P. O. Å Persson, A. E. Reiter, L. Hultman, and C. Mitterer, Scr. Mater. 54, 11 (2006).

59 H. O. Gekonde, and S. V. Subramanian, Surf. Coat. Technol. 149, 2-3 (2002).

60 S. H. Sheng, R. F. Zhang, and S. Veprek, Acta Mater. 56, 5 (2008).

61 B. Alling, A. Karimi, and I. A. Abrikosov, Surf. Coat. Technol. 203, 5-7 (2008).

62 L. Rogström, M. P. Johansson, N. Ghafoor, L. Hultman, and M. Odén, J. Vac. Sci. Technol. A 30, 3 (2012b). 
63 R. Lamni, R. Sanjines, M. Parlinska-Wojtan, A. Karimi, and F. Levy, J. Vac. Sci. Technol. A 23, 4 (2005).

64 H. Hasegawa, M. Kawate, and T. Suzuki, Surf. Coat. Technol. 200, 7 (2005).

65 L. Rogström, L. J. S. Johnson, M. P. Johansson, M. Ahlgren, L. Hultman, and M. Odén, Scr. Mater. 62, 10 (2010a).

66 L. Rogström, L. J. S. Johnson, M. P. Johansson, M. Ahlgren, L. Hultman, and M. Odén, Thin Solid Films 519, 2 (2010b).

67 Q. Luo, W. M. Rainforth, L. A. Donohue, I. Wadsworth, and W. Münz, Vacuum 53, 1-2 (1999).

68 R. Forsén, M. Johansson, M. Odén, and N. Ghafoor, J. Vac. Sci. Technol. A 30, 6 (2012).

69 I. W. Kim, Q. Li, L. D. Marks, and S. A. Barnett, Appl. Phys. Lett. 78, 7 (2001).

70 A. Madan, I. W. Kim, S. C. Cheng, P. Yashar, V. P. Dravid, and S. A. Barnett, Phys. Rev. Lett. 78, 9 (1997).

71 G. Abadias, A. Michel, C. Tromas, C. Jaouen, and S. N. Dub, Surf.Coat.Technol. 202, 4-7 (2007).

72 U. Helmersson, S. Todorova, S. A. Barnett, J. E. Sundgren, L. C. Markert, and J. E. Greene, J. Appl. Phys. 62, 2 (1987).

73 J. K. Park, H. J. Park, J. H. Ahn, and Y. J. Baik, Surf.Coat.Technol. 203, 20-21 (2009).

74 R. Forsén, N. Ghafoor, and M. Odén, J.Appl.Phys. 114, 24 (2013).

75 A. F. Jankowski, and T. Tsakalakos, J.Phys.F: Metal Physics 15, 6 (1985).

76 L. Hultman, C. Engström, and M. Odén, Surf.Coat.Technol. 133-134, (2000). 



\section{Included Papers}

The articles associated with this thesis have been removed for copyright reasons. For more details about these see:

http://urn.kb.se/resolve?urn=urn:nbn:se:liu:diva- 110684 